\title{
Ocean Acidification Amplifies the Olfactory Response to 2-Phenylethylamine: Altered Cue Reception as a Mechanistic Pathway?
}

\author{
Paula Schirrmacher $^{1}$ (D) . Christina C. Roggatz ${ }^{2}$. David M. Benoit ${ }^{3} \cdot$ Jörg D. Hardege $^{1}$
}

Received: 14 October 2020 / Revised: 25 March 2021 / Accepted: 13 April 2021 / Published online: 20 May 2021

(C) The Author(s) 2021, corrected publication 2021

\begin{abstract}
With carbon dioxide $\left(\mathrm{CO}_{2}\right)$ levels rising dramatically, climate change threatens marine environments. Due to increasing $\mathrm{CO}_{2}$ concentrations in the ocean, $\mathrm{pH}$ levels are expected to drop by 0.4 units by the end of the century. There is an urgent need to understand the impact of ocean acidification on chemical-ecological processes. To date, the extent and mechanisms by which the decreasing ocean $\mathrm{pH}$ influences chemical communication are unclear. Combining behaviour assays with computational chemistry, we explore the function of the predator related cue 2-phenylethylamine (PEA) for hermit crabs (Pagurus bernhardus) in current and end-of-the-century oceanic $\mathrm{pH}$. Living in intertidal environments, hermit crabs face large $\mathrm{pH}$ fluctuations in their current habitat in addition to climate-change related ocean acidification. We demonstrate that the dietary predator cue PEA for mammals and sea lampreys is an attractant for hermit crabs, with the potency of the cue increasing with decreasing $\mathrm{pH}$ levels. In order to explain this increased potency, we assess changes to PEA's conformational and charge-related properties as one potential mechanistic pathway. Using quantum chemical calculations validated by NMR spectroscopy, we characterise the different protonation states of PEA in water. We show how protonation of PEA could affect receptor-ligand binding, using a possible model receptor for PEA (human TAAR1). Investigating potential mechanisms of pH-dependent effects on olfactory perception of PEA and the respective behavioural response, our study advances the understanding of how ocean acidification interferes with the sense of smell and thereby might impact essential ecological interactions in marine ecosystems.
\end{abstract}

Keywords Chemically-mediated behaviour · Ligand protonation · Pagurus bernhardus · TAAR1 receptor .

Chemoattractant $\cdot$ DFT

\section{Introduction}

Chemical signalling mediates behaviour, development and physiology in many marine ecosystems (Hay 2009). However, the chemical marine environment is changing rapidly due to ocean acidification (Doney et al. 2009). The continuing uptake of atmospheric carbon dioxide $\left(\mathrm{CO}_{2}\right)$ into

Paula Schirrmacher

P.Schirrmacher-2018@hull.ac.uk

1 Department of Biological and Marine Sciences, University of Hull, Hull, HU6 7RX, UK

2 Energy and Environment Institute, University of Hull, Hull, HU6 7RX, UK

3 E.A. Milne Centre for Astrophysics, G.W. Gray Centre for Advanced Materials, Department of Physics and Mathematics, University of Hull, Hull, HU6 7RX, UK the ocean changes the seawater carbonate chemistry and reduces the $\mathrm{pH}$. As a consequence, global average ocean $\mathrm{pH}$ has already decreased by more than 0.1 since pre-industrial times to $\mathrm{pH} 8.1$ and is predicted to drop further to $\mathrm{pH} 7.7$ by the end of the century (Bopp et al. 2013; IPCC 2014).

This is of highest concern for marine animal behaviour (Clements and Hunt 2015). Although Clements and Hunt (2015) report primarily negative impacts of ocean acidification on the behaviour of marine organisms, the direction and magnitude of change depend on the species, ecosystem and type of behaviour, with some even improving in efficiency under ocean acidification conditions.

Although chemical cues and signals shape trophic cascades, structure communities and mediate food webs (Hahn et al. 2019; Cohen and Forward 2003; Poulin et al. 2018), an abundance of marine chemical stimuli are still unknown, impeding our understanding of the susceptibility of chemical communication to ocean acidification. To expand our 
knowledge, we draw an example from the terrestrial environment and choose to work with 2-phenylethylamine (PEA), a known dietary predator odour that is detected in the urine of most mammals (Ferrero et al. 2011). In aquatic systems, sea lampreys are known to avoid the smell of PEA (Imre et al. 2014; Di Rocco et al. 2016). Although PEA has been suggested for pest control of sea lampreys (Siefkes 2017), little is known about its role in aquatic environments. Many freshwater and marine algae are known to produce neurotransmitter-like compounds such as PEA (Van Alstyne et al. 2019). In marine environments, PEA has been reported in brown and red macroalgae in Germany and Turkey (Steiner and Hartmann 1968; Percot et al. 2009). Thereby, PEA has been hypothesised to function as a feeding deterrent (Smith 1977). As PEA is known to be present in the marine environment (Steiner and Hartmann 1968) and known to function as a dietary predator cue for many species (Ferrero et al. 2011; Imre et al. 2014), it's role for marine organisms in current and end-of-the-century average $\mathrm{pH}$ conditions needs to be further explored.

In the present study, we work with marine hermit crabs (Pagurus bernhardus) to determine the role of the predator-associated cue PEA in present and future $\mathrm{pH}$ conditions. Almost 800 species of hermit crabs (anomuran decapod crustaceans) inhabit a variety of marine environments (Hazlett 1981). Pagurus bernhardus is the most common hermit crab in British intertidal environments, occupying empty gastropod shells to protect their fragile abdomen (Lancaster 1988). Hermit crabs are known to respond to predator odours by altering their behaviour (Rosen et al. 2009) and their social interactions, shell selection and foraging rely on chemical signalling (Gherardi and Tricarico 2010). Whilst the average annual changes in ocean acidity due to climate change are small compared to the short life span of hermit crabs, the crustaceans routinely experience high fluctuations in acidity and temperature; Living in intertidal zones, hermit crabs inhabit environments of extremes (Wolfe et al. 2020). The $\mathrm{pH}$ variability over a single tide varies with the location but mostly exceeds the average $\mathrm{pH}$ change of 8.1 to 7.7, expected in the face of climate change. Moreover, climate change increases the range of $\mathrm{pH}$ fluctuation (Landschützer et al. 2018), exposing animals more frequently to potentially stressful conditions. Ocean acidification, in the context of this study, therefore comprises different time frames from natural diurnal changes to climate change.

We hypothesise that the response to PEA is $\mathrm{pH}$ dependent, with an effect observable within the range of ocean acidification as expected by the end of the century. We then investigate the relevance of different possible pathways by which $\mathrm{pH}$ can interfere with the observed behaviour. Mechanistically, info-disruption associated with ocean acidification has been linked to GABA receptor functioning in fish: the internal compensation for elevated $\mathrm{CO}_{2}$ conditions leads to altered brain ion gradients, interfering with neurotransmitter functioning (Nilsson et al. 2012; Williams et al. 2019). Electrophysiological and transciptomic measurements also revealed an impaired olfactory system in elevated $\mathrm{CO}_{2}$ conditions (Porteus et al. 2018). Furthermore, protonation through $\mathrm{pH}$ variation associated with climate change scenarios can change the structure and function of signaling cues and thereby affect olfactory perception (Roggatz et al. 2016; Brown et al. 2002). In this study, we consider four mechanisms by which the decreased $\mathrm{pH}$ can lead to an altered hermit crab behaviour (Fig. 1). We discuss the effect of a decreased $\mathrm{pH}$ on the signal source (pathway 1), quantify the role of the direct effects of $\mathrm{pH}$ on the signalling molecule and its interaction with the receptor (pathway $2 \& 3$ ) and discuss a potential interference of ocean acidification with signal transduction in hermit crabs (pathway 4).

To advance our understanding of the underlying mechanisms of changing hermit crab response to PEA at decreased $\mathrm{pH}$, we use a range of quantum chemical methods to model the conformation, charge distribution and dipole moment of PEA in different $\mathrm{pH}$ conditions (see pathway 2 in Fig. 1).

To date, the conformation of PEA (see Fig. 2) has mostly been studied in gas phase in the uncharged state: rotational and infrared spectra found a strong preference for folded (gauche) conformations (Godfrey et al. 1995; López et al. 2007). Thereby, the interaction of the amino group with the $\pi$-system contributes largely to the stabilisation (Chiavarino et al. 2014; Bouchet et al. 2015). A direct interaction of PEA and one water molecule was found when 1:1 PEAwater clusters were identified in gas phase (Dickinson et al. 1998; Hockridge and Robertson 1999). Further studies applied infrared and rotational spectroscopy paired with computational chemistry to confirm a gauche 1:1 PEAwater complex (Melandri et al. 2010; Bouchet et al. 2016). Recently, the hydration properties of neutral and protonated PEA $\left(\mathrm{PEAH}^{+}\right)$were also assessed in molecular dynamics simulations revealing a potential conformational preference for gauche PEA-water clusters for both protonation states (Ristić et al. 2019). Although PEA is found in aquatic environments, to the best of our knowledge, no study has yet addressed solvation effects on the potential energy curve of both protonation states of PEA. We hypothesise that both the conformation and charge distribution of $\mathrm{PEAH}^{+}$differ from its neutral state PEA and anticipate solvation playing a significant role.

To relate the computational method to the reality of PEA in water, we compare its calculated structure to NMR spectroscopic measurements. This allows us to validate the computational results.

We also explore the effect of ligand protonation on the receptor binding using quantum chemical calculations. To 


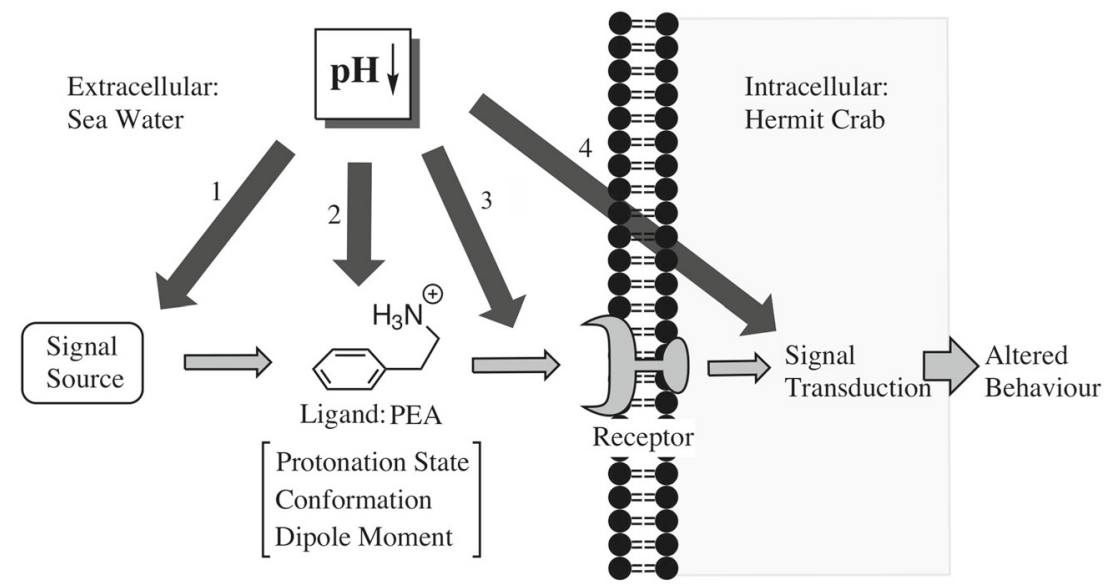

Fig. 1 Visualisation of the possible mechanisms by which decreased $\mathrm{pH}$ can result in an alteration in hermit crab response to PEA. The pathway of signal transmission from source to response is shown with light grey arrows. The potential mechanisms of a decreased $\mathrm{pH}$ interfering with this pathway are shown in dark gray and numbered. Thereby the decreased $\mathrm{pH}$ can affect the signal source (1), the signalling cue (2),

the receptor or its interaction with the ligand (3) and the signal transduction (4). In this study, the hypothesised scenarios are pathway 2 \& 3 , whereby the decreased $\mathrm{pH}$ alters crucial characteristics of the signalling molecule and subsequently its interaction with the receptor. This ultimately affects the behavioural response

provide a proof a principle, we study the interaction of PEA with the binding pocket of the human trace amineassociated receptor 1 (TAAR1), whose primary endogenous ligand is PEA. TAAR receptors are known vertebrate olfactory receptors (Liberles 2015). However, whilst the olfactory activation of TAAR4 is known to elicit a fear response in rodents, TAAR 1 mostly functions in the vertebrate brain (Liberles 2015). As the binding pocket and $3 \mathrm{D}$ structure of olfactory TAAR receptors is not well explored, we chose to work with a homology model of TAAR1 instead, which is described in the literature (Cichero et al. 2013). Electrostatic interactions are essential for receptor-ligand interactions (Leckband et al. 1992) and protonation of the chemical signal can affect its electronic properties (Radić et al. 1997). We hypothesise therefore, that the protonation of PEA substantially alters its receptor binding properties. To the best of our knowledge, this is the first study to explore the effect of $\mathrm{pH}$ change on receptor-ligand interactions.

This study evaluates the effect of PEA on a marine crustacean at current average $\mathrm{pH}$ and end-of-the-century levels, linking behavioural assays with computational chemistry. To determine the functionality of the cue we start by exploring behavioural reactions of hermit crabs in different $\mathrm{pH}$ conditions. These lead us to examine the properties of the different protonation states of PEA in water using quantum chemical calculations. The computational findings are then compared with measurements of PEA in water using NMR spectroscopy. Ultimately, we assess the effect of protonation on the interaction of PEA with the potential receptor model TAAR1 and draw conclusions on the possible mechanisms by which a decreasing ocean $\mathrm{pH}$ can affect the behavioural response to a chemical signal.
Fig. 2 Conformations of protonated PEA $\left(\mathrm{PEAH}^{+}\right)$with torsion angle $\tau$ of the amino side chain in dark red. The anti conformation (a) corresponds to an extended geometry with $\tau \approx 180^{\circ}$. The torsion angle of the folded conformation (gauche, b) is $\tau \approx \pm 60^{\circ}$ and leads to a weak $\pi$-hydrogen bond (dotted line)
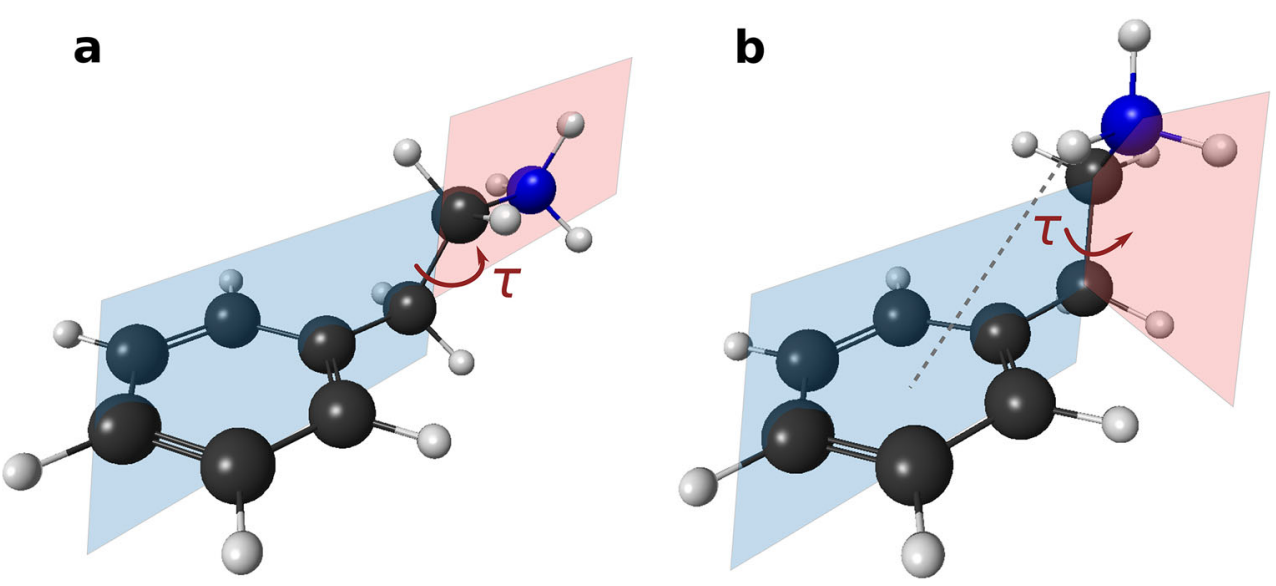


\section{Materials and Methods}

\section{Hermit Crab Collection and Culture}

P. bernhardus were collected by hand from the rocky intertidal shore near Scarborough (54²5'19.6”N 031'43.6”W), UK, in November 2018. At the aquaria facilities of the University of Hull, the hermit crabs were kept at $\mathrm{pH} 8.1 \pm 0.1$ and acclimatised to a twice weekly feeding rhythm with commercially available cooked blue mussels and kept at an average temperature of $15.8 \pm 0.2^{\circ} \mathrm{C}$ and $35.9 \pm 0.2 \mathrm{PSU}$.

\section{Behavioural Assay to Determine Cue Functionality}

To determine the reaction of hermit crabs to PEA, the animals ( $\mathrm{n}=20$ per $\mathrm{pH}$ condition) were not fed for 5-7 days and randomly allocated to be tested in $\mathrm{pH}$ condition 7.7 and 8.1. Skipping a feed ensured a tight control on the hermit crab's appetite level, ensuring their potential interest in a feeding cue. The light was dimmed to reduce the impact of visual stimuli. After being acclimatised to the $\mathrm{pH}$ of the new environment for up to 2 minutes in a separate tank, each individual was tested for its reaction to PEA (2-phenylethylamine hydrochloride, Sigma-Aldrich, $98 \%$ ). Thereby, three concentrations were tested subsequently with up to 2 minute acclimation time in a seperate tank between the assays. As negative control, the undisturbed movement pattern of each individual in their allocated $\mathrm{pH}$ condition and tank was observed in an experiment without chemical cues. This experiment helps to identify a potential bias of movement due to light, preference of side and other visual effects. The tank $(28 \mathrm{~cm} \times 18 \mathrm{~cm})$ contained $1 \mathrm{~L}$ of artificial sea water with $\mathrm{pH} 7.7$ or 8.1 . Crabs were individually caged with a plastic cylinder in the middle of the tank and filter papers (Whatman No. 3, $1 \mathrm{~cm}^{2}$ ) were dropped on either side of the tank. In the negative control experiment, both filter papers were blank. In the three PEA conditions, the filter paper on one side contained $200 \mu \mathrm{L}$ of the respective PEA concentration $\left(3 \cdot 10^{-6} \mathrm{~mol} / \mathrm{L}, 3 \cdot 10^{-5} \mathrm{~mol} / \mathrm{L}\right.$ and $3 \cdot 10^{-4} \mathrm{~mol} / \mathrm{L}$ ) while the paper was left empty on the other side of the tank (control). The side of the PEA filter paper was randomised. After allowing the cue to diffuse for 20 seconds, the crab was released by lifting the plastic cylinder and observed for 2 minutes.

Additionally, experiments with black liquid food dye (200 $\mu \mathrm{L}, 1: 10$ dilution, Dr. Oetker) on filter paper (Whatman No. 3) were carried out to determine the effects of the lifted cage and moving hermit crab on the diffusion of PEA in the tank water during the experiment. Before lifting the cage streaks of the dye diffuse to about a quarter of the tank. Diffusion over time, lifting the cage and the movement of the animal lead to movement and mixing of the otherwise stationary tank water. The filter paper, however, remained the primary source of the chemical cue in the tank until the end of the experiment.

For the data analysis, the tank was virtually divided into thirds (see Fig. 3) and the time spent in each of the three areas was recorded manually or by video to ensure consistency.

By manipulating the $\mathrm{pH}$ of the bioassay water with $\mathrm{HCl}$ instead of $\mathrm{CO}_{2}$ we are able to focus on the effect of $\mathrm{pH}$ and manipulate only the proton concentration in the water (Gattuso et al. 2010). Leaving the carbon chemistry untouched allows us to study the isolated effect of $\mathrm{pH}$ on the behaviour of hermit crabs. Thereby we can directly compare the effect of $\mathrm{pH}$ on the response of hermit crabs to PEA with the changes in conformation and charge of the signalling cue. This allows us to improve our understanding of the underlying mechanisms.

\section{Statistics}

All statistics were carried out with(version 3.2.3-4, R Core Team 2015). The behaviour assay, as described above, has a paired structure within the level of the individual crab as the same hermit crab was tested four times (negative control, three PEA concentrations). Applying a linear mixed effect model ('lme4' R package) (Bates et al. 2015) the effect of the concentration of PEA on the time spent in either area was tested for both $\mathrm{pH}$ scenarios ( $\mathrm{pH} 7.7$ and 8.1). Multiple comparisons of the response to PEA at different concentrations were carried out with Tukey's test using the 'multcomp' package in R (Hothorn et al. 2008).

\section{Computations of PEA}

The conformation of neutral and protonated PEA was studied using quantum chemical methods. The calculations

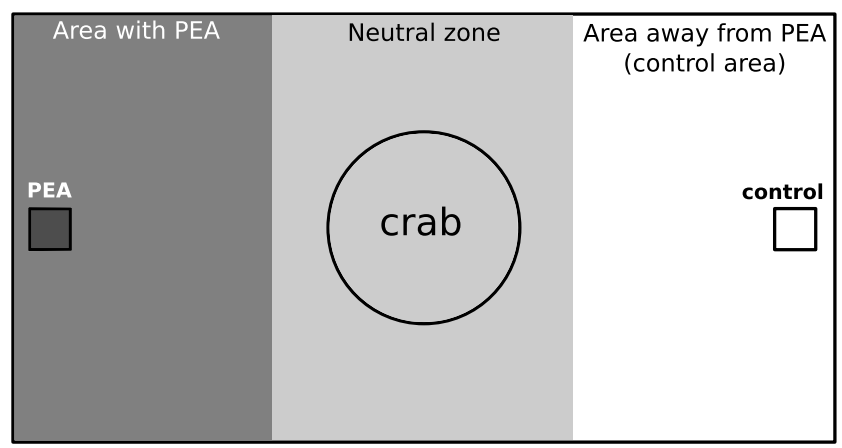

Fig. 3 Set-up of the behaviour experiment. The hermit crab was caged with a plastic cylinder in the middle of the neutral zone whilst the cues were dropped on either side of the tank on filter paper (squares). After 20 seconds of diffusion time, the cylinder was lifted and the movement pattern of the hermit crab was observed or recorded by video for 2 minutes. For data analysis, the time spent in the three areas (dark gray, gray, white) of the tank was measured 
were carried out with the supercomputer (Viper) of the University of Hull and validated by NMR spectroscopy. Calculating the total energy of geometry-optimised PEA at different constrained torsion angles $\tau$ of the amino side chain allowed us to determine energetically favourable conformations and barrier heights (torsion angle energy scan). Due to the structure of PEA (Fig. 2), the position of the amino side chain is the main structural factor in the determination of energetically favoured geometries.

However, the aquatic environment in which PEA is dissolved also has to be taken into account. Longrange and short-range interactions with water can have a large impact on the conformation (Roggatz et al. 2018). Therefore, the torsion angle energy scan was studied in gas phase, in a dielectric infinite continuum of water using the CPCM approach (implicit solvent approach, Barone and Cossi 1998, Cossi et al. 2003) implemented in ORCA version 4.0.1 (Neese 2012, 2018) and in an implicit solvent environment including the interaction of one explicit water molecule with the amino group. One explicit water molecule per ionisable group was found to improve accuracy and reliability of isotropic nuclear magnetic shielding calculations (Roggatz et al. 2018).

Geometry optimisations in ORCA (version 4.0.1) were performed with the PBE0 exchange correlation functional (Adamo and Barone 1999) using a pc-2 basis set (Jensen 2001, 2002a, b). D3 dispersion correction (Grimme et al. 2010; Grimme et al. 2011) was included and the RIJ-COSX approximation (Neese et al. 2009) with a def2/J auxiliary basis set (Weigend 2006) was applied. The final point energy values for each geometry-optimised conformation were then plotted against the respective constrained torsion angle. To facilitate the comparison between the different environments, the total energy is shown relative to the energy in the gauche 1 conformation for each system. The identified minima were reoptimised without conformational restraints and their eigenvalues were checked for imaginary frequencies.

To model water implicitly, the bulk of the solvent is represented as a structureless polarisable medium that is characterized by its dielectric constant $\varepsilon$ (Barone and Cossi 1998; Cossi et al. 2003). A dielectric constant of 80.4 is generally used to include the aqueous background in computational models. However, experimentally, a dielectric decrement can be observed when salt is added to water (Hasted et al. 1948), leading to a dielectric constant of 72.5 for $35 \mathrm{ppt} \mathrm{NaCl}$ at $20^{\circ} \mathrm{C}$ (Klein and Swift 1977), which approximates the conditions during the behavioural experiments.

To explore the impact of the dielectric constant on solvation models of PEA and $\mathrm{PEAH}^{+}$within the range of $\mathrm{NaCl}$ effects in sea water, the previously optimised conformers of PEA and $\mathrm{PEAH}^{+}$in the implicit solvation model were reoptimised using ORCA (version 4.0.1, Neese 2012, 2018), specifying the dielectric environment as $\varepsilon$ $75.4,72.5,70.4$ or 65.4 within the CPCM. Geometry optimisations were performed as previously, with the PBE0 exchange correlation functional (Adamo and Barone 1999) using a pc-2 basis set (Jensen 2001, 2002a, b) and RIJ-COSX approximation (Neese et al. 2009) with a def2/J auxiliary basis set (Weigend 2006). D3 dispersion correction (Grimme et al. 2010, 2011) was included. The energy difference between extended and folded conformation, the torsion angle and the dipole moment were compared to the original results obtained with $\varepsilon=80.4$.

The molecular electrostatic potential (MEP) of energetically favoured conformations of $\mathrm{PEA} / \mathrm{PEAH}^{+}$was obtained using the GAMESS program (Schmidt et al. 1993, version 18/08/2016, R1) with the PBE0 exchange functional in conjunction with the pc-2 basis set (Jensen 2001, 2002a, b). Calculations were carried out with a polarisable continuum model. Using the wxMacMolPlt program (Bode and Gordon 1998, version 7.6), a threedimensional electron density isosurface was created with 100 grid points and a contour value of $0.1 \mathrm{e} \cdot \mathrm{a}_{0}^{-3}$. To visualise the MEP, the density isosurface was coloured with a maximum value of $0.9 \mathrm{E}_{h} \cdot \mathrm{e}^{-1}$ and the RGB colour scheme with red representing positive, green neutral and blue negative charge.

Isotropic nuclear magnetic shielding values of ${ }^{1} \mathrm{H}$ nuclei were calculated with ORCA (version 3.0.0) at the PBE0/aug-pc-2 level of theory (Jensen 2001, 2002a, b). As for the geometry optimisations, RIJ-COSX approximation with a def2-TZVPP/J auxiliary basis set was used. All nuclear shieldings calculations were run with the individual gauge for localized orbitals method (IGLO) (Kutzelnigg et al. 1990). The resulting nuclear shielding constants are compared to experimentally determined chemical shifts (see below).

\section{NMR Spectroscopy}

Samples for NMR measurements were prepared with 2phenylethylamine hydrochloride (Sigma-Aldrich, $98 \%$ ) at pH 11.8 and pH 6.8 to ensure a high percentage (>99\%) of PEA in the respective protonation state. PEA was measured at $0.05 \mathrm{~mol} / \mathrm{L}$ in $0.04 \mathrm{~mol} / \mathrm{L}$ sodium phosphate buffer to stabilise the $\mathrm{pH}$ during measurement with $10 \%$ deuterium oxide (Sigma-Aldrich) as solvent lock. NMR spectra were recorded on a JEOL ECZ 400S spectrometer with Tetramethylsilane (TMS, $50 \mu \mathrm{L}$, Sigma-Aldrich, >99.5\%) $\delta_{H}=0$ as the internal standard. 


\section{Computations of Receptor Binding}

32 amino acids, known to be involved in the ligand binding site (Cichero et al. 2013), were cut out of the human homology model of the TAAR1 receptor in the active state from the GPCR database (Pándy-Szekeres et al. 2018). The position and size of the chosen binding pocket is shown in Fig. 4. As the amino acids of the binding pocket are in their standard protonation state all are neutral but for Asp103, which is negatively charged. Using Avogadro (Hanwell et al. 2012, version 1.1.1), peptide bonds were added to cap the cutting sites. For this, a methyl group was introduced on the amino side, a nitrogen-methyl group was added to the unbound carboxyl side and hydrogens were added to the amino acid backbone. The molecular capping procedure of amino acids was adapted from the MFCC approach (Zhang and Zhang 2003).

The folded conformation of PEA/PEAH ${ }^{+}$, geometryoptimised in the implicit water model, was positioned in the center of mass of the binding pocket facing Asp103, as this was the binding point in previous studies (Cichero et al. 2013). All added methyl groups, nitrogen and

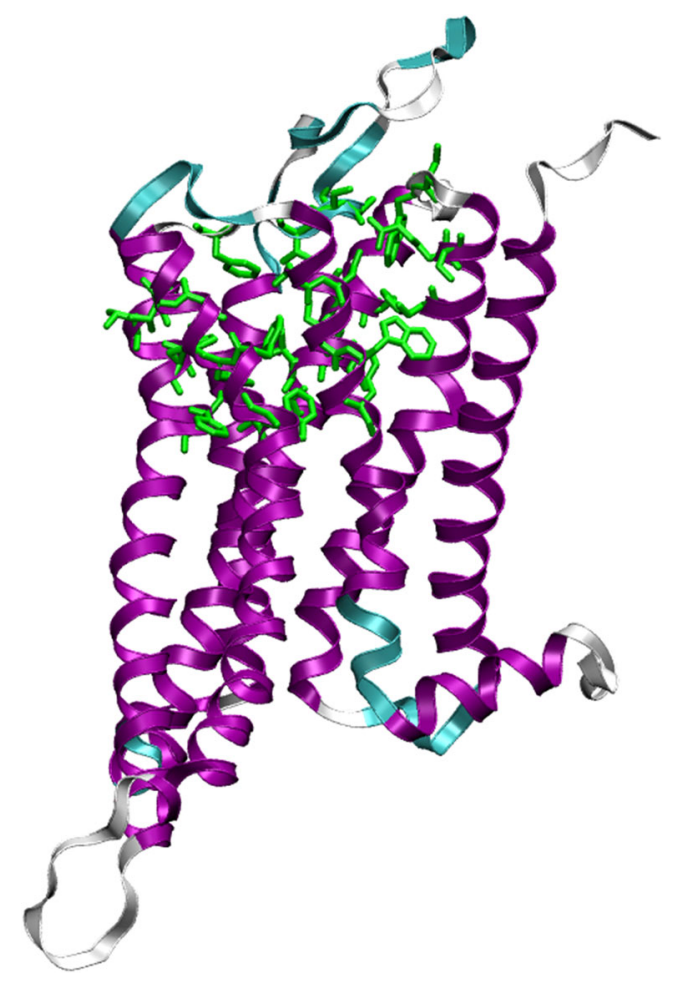

Fig. 4 Secondary structure of the TAAR1 receptor with the alpha helix in purple, turns in cyan and coils in white. The amino acids of the binding pocket are shown in green stick representation. The majority of the chosen binding pocket is part of the alpha helix hydrogen atoms were allowed to optimise using universal force field (Rappé et al. 1992) in Avogadro. Keeping PEA/PEAH ${ }^{+}$and the amino acid backbone constrained, the manually added atoms were then reoptimised using the PBE functional (Perdew et al. 1996) with D3 dispersion correction (Grimme et al. 2010, 2011) and SZV-MOLOPTGTH basis set (VandeVondele and Hutter 2007; Krack 2005) in CP2K (VandeVondele et al. 2005, version 6.1; Hutter et al. 2014).

In the following, the binding pocket was placed inside a spherical cavity with radius $18.12 \AA$, outside which a dielectric continuum simulated the protein background. For this, the self-consistent reaction field (SCRF) method (Wong et al. 1991) with a dielectric constant of 8 was applied. Previous studies showed that the protein environment in an enzymatic reaction can be adequately represented by embedding the active site in a dielectric cavity with the dielectric constant $\varepsilon=8$ (Siegbahn and Himo 2009). However, water penetration can affect local structures and polarisability inside proteins, potentially requiring higher dielectric coefficients (Fitch et al. 2002), whilst salt is known to decrease the dielectric constant (Hasted et al. 1948). To explore the potential effect of water and salt on the microenvironment of TAAR 1 we conducted a set of computational experiments, manipulating the dielectric constant in the SCRF model: In addition to the protein background modelled with $\varepsilon=8$, the effect of potential water penetration on the dielectric background is explored by comparing the original model (SCRF with $\varepsilon=8$ ) to the same model optimised with a dielectric constant of 10 . To assess potential long-range effects of salt ions on the receptor-ligand binding, the effect of a dielectric decrement to $\varepsilon=6-4$ is also studied. The size of the cavity for the TAAR1 receptor binding pocket was chosen to contain the van der Waals radii of all atoms. PEA/PEAH ${ }^{+}$ was then allowed to optimise inside the constrained binding pocket using the PBE functional (Perdew et al. 1996) with D3 dispersion correction (Grimme et al. 2010, 2011) and TZV2PX-MOLOPT-GTH basis set (VandeVondele and Hutter 2007; Krack 2005) in CP2K. Thereby, the poisson solver (Blöchl 1995; Martyna and Tuckerman 1999) was used to isolate the $(40 \AA)^{3}$ boxes in the periodic environment. By default, $\mathrm{CP} 2 \mathrm{~K}$ introduces a uniform background charge in charged periodic systems.

To determine the effect of the charge of PEA on the receptor binding, $\mathrm{PEAH}^{+}$and neutral PEA were optimised with the same starting conformation and position. For neutral PEA, all three positions of the electron lone pair in the starting conformation were compared and the energetically favoured conformation was chosen. 


\section{Results}

\section{Role of PEA for Hermit Crabs}

The choice experiment with hermit crabs reveals that PEA is an attractant for hermit crabs. In $\mathrm{pH} 8.1,12$ out of 20 hermit crabs spent more time in the area with the cue $\left(3 \cdot 10^{-4} \mathrm{~mol} / \mathrm{L}\right)$ than during the respective negative control experiment and 14 out of 20 hermit crabs preferred the area with PEA in $\mathrm{pH}$ 7.7. Figure 5 shows that whilst the time spent in the third of the tank furthest away from the cue decreased in a clear dose-dependent manner (Fig. 5a), the time spent in the area with PEA increased subsequently (Fig. 5b).

The response of hermit crabs in the control experiments are comparable in both $\mathrm{pH}$ conditions, indicating that the decreased $\mathrm{pH}$ in the absence of a signalling cue has no measurable effect on their general behaviour. The attractive effect of PEA is stronger at low pH. At pH 7.7, the hermit crabs spend significantly more time in the area with PEA during the highest exposure experiment $\left(3 \cdot 10^{-4} \mathrm{~mol} / \mathrm{L}\right)$ than during the negative control experiment (post-hoc Tukey's test, $p<0.01$, on average $27 \%$ ). On the other hand, the dose-dependent response to PEA is not significant at $\mathrm{pH}$ 8.1 (chi-squared test, $p=0.29$ ). The date of the experiment had no significant effect on the model, testifying the rigorousness of the procedure. A table of the recorded times and conditions of the behaviour experiment can be found in Online Resource 1.

\section{Conformation and Charge Distribution of PEA at Different pH and in Different Environments}

The $360^{\circ}$ torsion angle energy scans shown in Fig. 6 reveal three energetically favoured conformations for both, neutral and protonated PEA. An extended (anti) and two folded

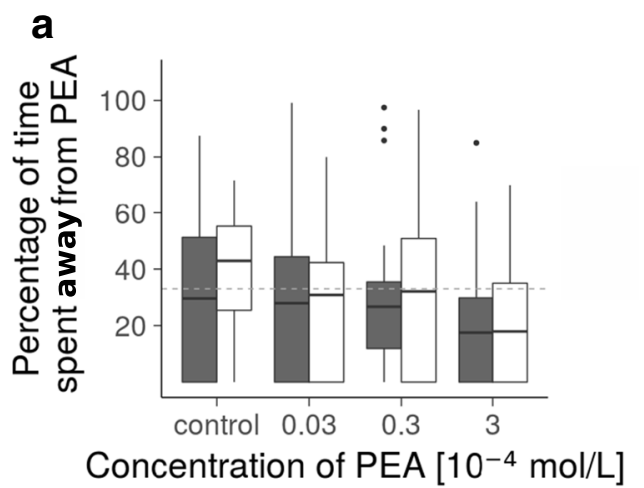

Fig. 5 Behavioural response of hermit crabs $(n=20)$ to PEA at current $\mathrm{pH}$ (8.1) and end-of-the-century level (7.7). Percentage of time spent in the third of the tank furthest away from PEA (a) and near the PEA source (b) at different PEA concentrations. The dashed gray line indicates a third of the time. At pH 7.7 (dark gray), hermit crabs spent (gauche) conformations were found to be energetic minima in all three environments (Table 1). It is important to note that especially the gauche 1/gauche 2 energetic differences are very close to the limit of chemical accuracy, making a precise conformational prediction difficult.

Solvation has a clear effect on the scan profile. This results in different relative stabilities of the energetic minima with slightly differing torsion angles and different barrier heights depending on the environment. Figure $6 a \&$ $\mathrm{b}$ compare the energy scans as a function of the torsion angle in three environments: in gas phase, in a conductor-like polarisable continuum model (implicit water model) and in the implicit water environment including one explicit water molecule interacting with the amino group (hybrid water model).

The neutral PEA scan (Fig. 6a) shows an asymmetry in the relative stability of the two folded conformations (gauche $1 \tau \approx-60^{\circ}$, gauche $2 \tau \approx+60^{\circ}$ ). This can be explained by the asymmetry of the amino group, containing two hydrogen atoms $\left(\mathrm{H}_{\mathrm{N}}\right)$ and an electron lone pair. In the gauche conformation either $\mathrm{H}_{\mathrm{N}}$ or the nitrogen lone pair are interacting with the aromatic ring, leading to different relative stabilities. The environment, however, has a clear impact on these energetic differences. In the implicit water model, the gauche 2 conformation with lone pair- $\pi$ interaction $\left(\tau \approx+60^{\circ}\right)$ is stabilised compared to the gas phase. This effect becomes more pronounced with the inclusion of an explicit water molecule (hybrid water model), which reverses the relative stabilities of the folded conformations. Whilst gauche 1 was the stable folded conformation in gas-phase and in the implicit water model, gauche 2 is favoured in the hybrid water model. This is due to the hydrogen atoms of the water molecule forming hydrogen bonds with the nitrogen lone pair and the $\pi$ system on either side and thereby promoting the energetic stability (Fig. 6c). The distance between the amino group

b

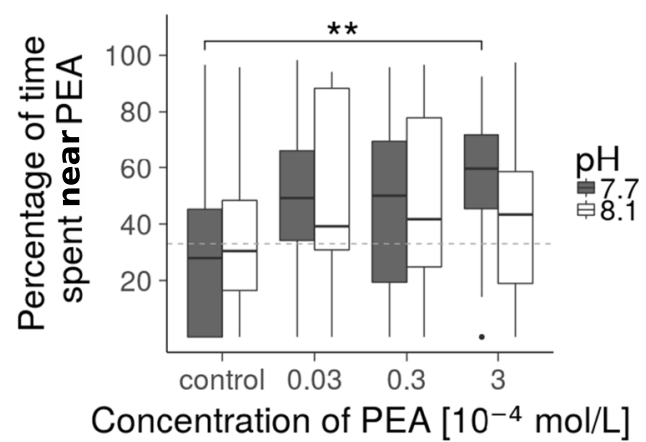

significantly more time near the highest dose ( $b, p<0.01$, indicated by bracket with asterisks). There was no significant difference at $\mathrm{pH} 8.1$ (white). The boxplot depicts the median with first and third quartile of the distribution. Whiskers extend to $1.5 \times$ the interquartile range; data beyond that range are defined as outliers and plotted individually 
Fig. 6 Energy scan around the amino side chain torsion angle of neutral (a) and protonated (b) PEA, and the interaction of water with the folded conformations of neutral PEA gauche 2 (c) and gauche 1 (d). Energy values are relative to the energy of the gauche 1 conformation calculated in the respective environment. Conformations for selected torsion angles are depicted in a filmstrip above the scan. Favoured geometries are energetic minima; both protonation states show minima at one extended and two folded conformations. The potential energy curve in two solvation models are compared to gas phase (red circles). The implicit water model (blue squares) is extended by including the interaction of one explicit water molecule with the amino group (hybrid water model, green triangles). As only one water molecule is added, this scan is asymmetric. Hydrogen atoms are depicted in white, carbon atoms in black, nitrogen atoms in blue and oxygen atoms in red a
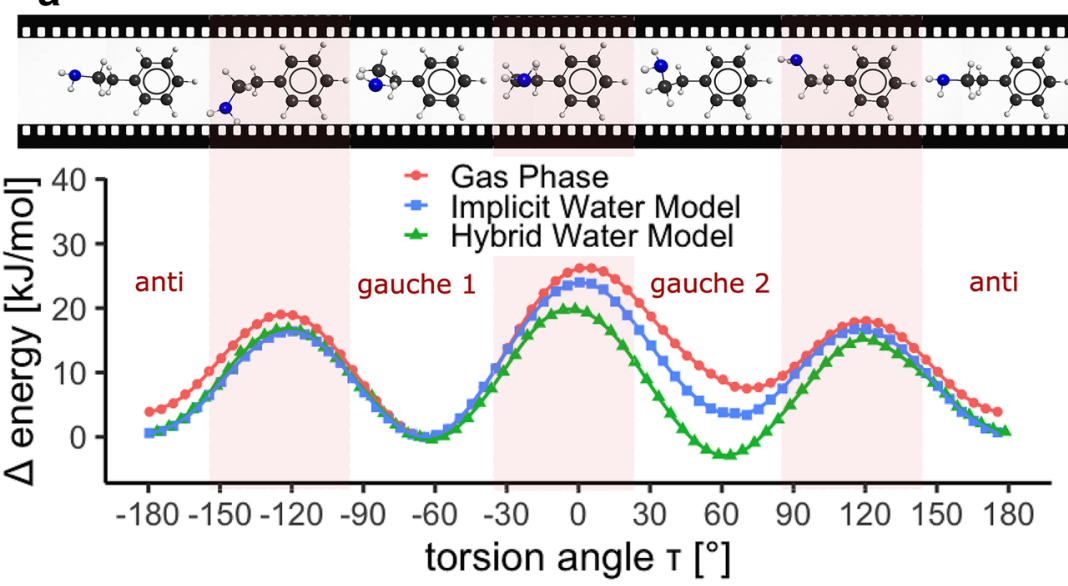

b
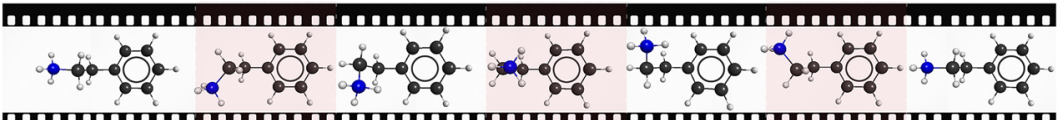

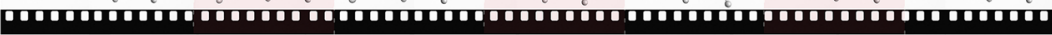

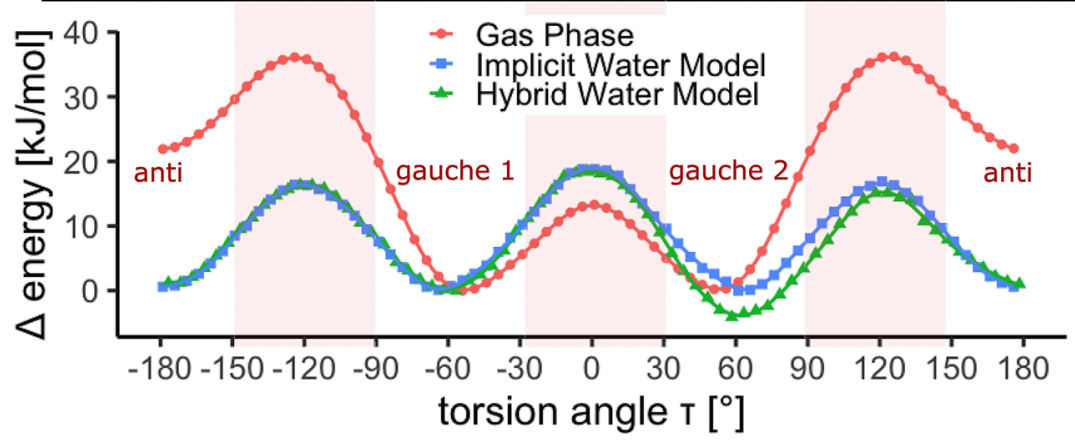

C

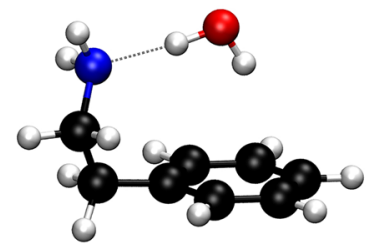

d

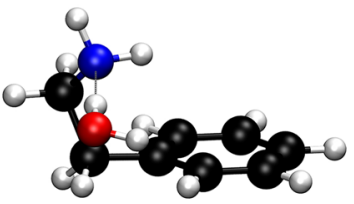

hydrogen atom closest to the benzene ring and the $\pi$-system is $3.28 \AA$ for the gauche 1 conformation (Fig. 6d) whilst the distance between the $\pi$-system and the water hydrogen atom is $2.48 \AA$ (gauche 2, Fig. 6c). As oxygen atoms are known to be rather weak hydrogen-bond acceptors compared to nitrogen atoms (Böhm et al. 1996), the nitrogen lone pair of PEA interacts with the water hydrogen atom rather than PEA forming a bond between the nitrogen hydrogen atom and water oxygen atom.

Overall, solvation has a strong effect on $\mathrm{PEAH}^{+}$ (Fig. 6b). The difference between the gas phase model and the solvation models are particularly pronounced in the relative stability of the extended conformation $\left(\tau \approx \pm 180^{\circ}\right)$
Table 1 Torsion angles $\tau$ and energy differences $\Delta E$ of the energetically favoured conformations of PEA and $\mathrm{PEAH}^{+}$in solvation as determined with the hybrid water model. The energetic minima were optimised without geometrical constraint and the energy of the explicit water molecule was substracted. Energy differences are shown relative to the lowest energy conformation

\begin{tabular}{llllll}
\hline & \multicolumn{2}{l}{ PEA } & & & \multicolumn{2}{c}{$\mathrm{PEAH}^{+}$} \\
\cline { 2 - 3 } \cline { 5 - 6 } & $\Delta E[\mathrm{~kJ} / \mathrm{mol}]$ & $\tau\left[{ }^{\circ}\right]$ & & $\Delta E[\mathrm{~kJ} / \mathrm{mol}]$ & $\tau\left[{ }^{\circ}\right]$ \\
\hline anti & 3.5 & 178.1 & & 4.5 & 179.8 \\
gauche 1 & 1.2 & -60.8 & & 3.9 & -59.0 \\
gauche 2 & 0 & 61.8 & & 0 & 60.6 \\
\hline
\end{tabular}


and the barrier height between the folded and extended conformation. The implicit water model stabilises the anti conformation. Adding one explicit water molecule (hybrid water model) decreases the relative energy of one of the folded conformations. Similarly to neutral PEA, the folded conformation with the water mediating between the amino group and the aromatic ring is the most stable form for protonated PEA in the hybrid model. In this conformation, the distance between the hydrogen atom of the water molecule and the $\pi$-system is $2.39 \AA$.

The conformations of the energetic minima deduced from the torsion angle energy scans were also optimised with released torsion angle constraints. In water, gauche is energetically favoured over the anti conformation for both protonation states. After substracting the energy of the water molecule, the torsion angles and energy differences for the hybrid solvation model are shown in Table 1 . The xyz-files of the energetic minima in gas-phase, in the implicit and hybrid water model can be found in Online Resource 2.

The torsion angle energy scans (Fig. 6a \& b) are asymmetric, reflecting the range of energetically favoured conformations for PEA and PEAH ${ }^{+}$. It is important to note, however, that neutral and protonated PEA both have two degenerate (i.e. same energy level) folded conformations as their absolute energetic minimum. By rotation around the $\mathrm{C}$ $\mathrm{N}$ bond, the flexible amino side chain enables the molecule to lock into the same folded conformation for negative as well as positive torsion angles.

The relative population of the different conformations is governed by the energy difference and the temperature of the system. By calculating the Boltzmann factor, the energy differences (Table 1) can be translated into relative populations.

With an ocean annually-averaged temperature of $17^{\circ} \mathrm{C}$ for 2018 (NOAA 2019), the ratio of extended to folded conformation is $1: 9$ for neutral PEA and 1:13 for PEAH ${ }^{+}$. Decreasing the $\mathrm{pH}$ leads to an increase in the population of the folded conformation.

Both, neutral PEA and $\mathrm{PEAH}^{+}$show charge separations in the amino group and $\mathrm{C}-\mathrm{H}$ bonds (Fig. $7 \mathrm{a} \& \mathrm{~b}$ ). $\mathrm{PEAH}^{+}$ is overall more positively charged (red in Fig. $7 \mathrm{a} \& \mathrm{~b}$ ) than PEA, whereby the difference in the charge distribution is particularly pronounced in the amino group. The dipole moment can be used as a measure of the charge separation. Even in the same folded conformation, protonated and neutral PEA differ in magnitude and direction of the dipole moment (red arrow in Fig. 7c \& d). The dipole moment for folded neutral PEA is $2.5 \mathrm{D}$ whilst it is $12.6 \mathrm{D}$ for $\mathrm{PEAH}^{+}$ in the same conformation.

Furthermore, to explore the effect that different $\mathrm{NaCl}$ concentrations in the water could have on our model, a series of experiments manipulating the dielectric constant were carried out. The detailed results are described in the
Supplementary Information. In short, we show that the effect of the ionic environment is negligible within the range of accuracy of our model.

\section{NMR Spectroscopy}

To validate the quantum chemical computations, nuclear proton shieldings of the energetic minima of PEA and $\mathrm{PEAH}^{+}$were calculated in the hybrid water model (as described by Roggatz et al. 2018). The calculated ${ }^{1} \mathrm{H}$ shieldings were compared to experimental shifts measured in water.

The validation of the computational method using NMR spectroscopy is described further in the Supplementary Information. In brief, the correlation of the experimental data with the calculated shieldings for the different energetic minima were compared using linear models. This confirmed that the folded conformations, which are the computationally identified global energetic minima, fit best with the experimental values. As calculated, the folded conformation is the energetically favoured conformation in water for both protonation states. ${ }^{1} \mathrm{H}$ NMR spectroscopy verifies the computational findings, showing a close fit with the hybrid water models of PEA and PEAH ${ }^{+}$.

\section{Comparison of Biological and Chemical Effect}

To quantify the biological effect, the difference in the percentage of time spent near the cue at the highest concentration and the respective negative control experiment can be determined for the two $\mathrm{pH}$ environments. Fig. 8 shows that hermit crabs at $\mathrm{pH} 7.7$ spend on average $21 \%(25 \pm 14$ seconds) more time in the area with PEA at its highest concentration $\left(3 \cdot 10^{-4} \mathrm{~mol} / \mathrm{L}\right.$ ) than at $\mathrm{pH} 8.1$ (one-sided t-test, $p=0.04$ ).

Using the Hendersson-Hasselbalch equation (eq. 1), the percentage of protonated and neutral PEA at different $\mathrm{pH}$ can be estimated (Fig. 8b).

$p \mathrm{H}=p K_{a}+\log _{10}\left(\frac{\left[A^{-}\right]}{[H A]}\right)$

With a $p K_{a}$ of 9.83 (Lide 2000), PEA is mostly protonated in aquatic environments. At $\mathrm{pH} 8.198 .0 \%$ and at $\mathrm{pH} 7.7$ $99.3 \%$ of PEA are in the charged state. The difference in protonation states between the two experimental conditions is therefore $1.3 \%$.

The absolute increase in the abundance of $\mathrm{PEAH}^{+}$is small. However, our calculations show that the dipole of PEA increases 5-fold upon protonation (see above), potentially leading to an increased binding energy to its receptor. 
Fig. 7 Charge distributions (a \& b) and dipole moment (c \& d) of folded PEA in the implicit solvation model in the protonated (b \& d) and neutral state (a \& c). Electron density isosurfaces $(\mathbf{a} \& \mathbf{b})$ are colour-coded according to the molecular electrostatic potential with blue representing negative, green neutral and red positive charge. The $30 \%$ transparency of the electron density surface shows the conformation of the molecule underneath with hydrogen atoms in white, carbon atoms in black and nitrogen atoms in blue. The dipole moment (c \& d) is represented by a red arrow pointing from negative to positive charge

\section{Receptor-Ligand Interaction in Different pH Conditions}

The protonation state of PEA has a clear effect on its orientation and conformation inside the TAAR1 binding pocket (Fig 9).

Starting the geometry optimisation of $\mathrm{PEA} / \mathrm{PEAH}^{+}$in the center of mass of the binding pocket, the root-meansquare deviation between the atomic positions of protonated and neutral PEA is $2.1 \AA$ after geometry optimisation. The final torsion angle $\tau$ of the amino group side chain (see Fig. 2) of neutral PEA is $82.9^{\circ}$ whilst $\mathrm{PEAH}^{+}$adopts a torsion angle of $66.5^{\circ}$ inside the binding pocket, compared to $61.8^{\circ}$ and $60.6^{\circ}$ respectively in the non-complexed state. Furthermore, $\mathrm{PEAH}^{+}$establishes a strong hydrogen bond with the negatively charged Asp103 (Fig. 9b) whilst the position of neutral PEA is mainly guided by conformational preferences (Fig. 9a). The distance between the closest amino group hydrogen atom of PEA and the negatively a
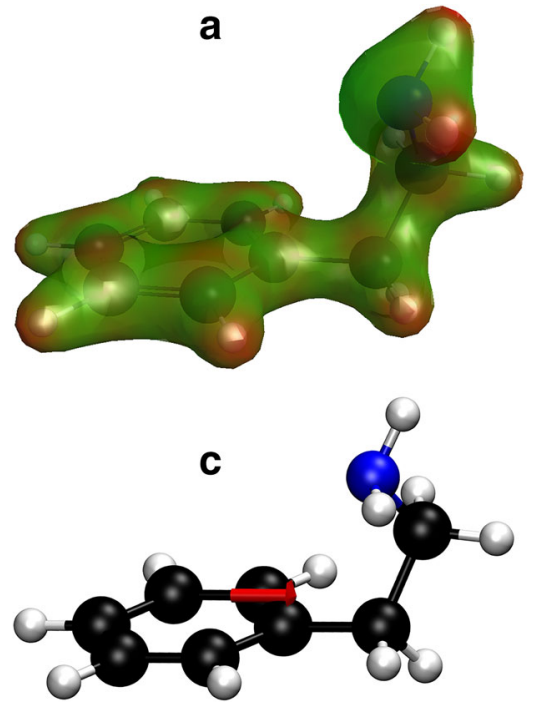
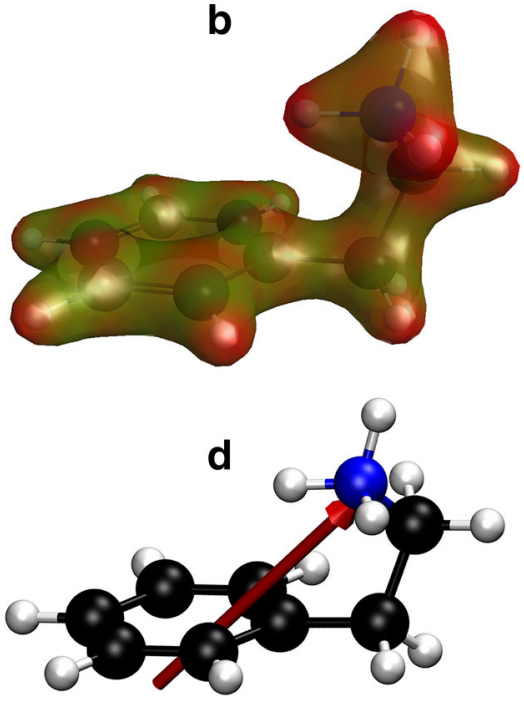

charged carboxyl group of Asp103 is $2.2 \AA$ for neutral PEA whilst it is $1.4 \AA$ for $\mathrm{PEAH}^{+}$(see dotted line in Fig. 9). The distance between the PEA nitrogen atom and the aspartate oxygen atom is $3.1 \AA$ for neutral PEA and $2.5 \AA$ for $\mathrm{PEAH}^{+}$. Also, the angle of the hydrogen bond between PEA and aspartate increases upon protonation from $147.2^{\circ}$ to $169.8^{\circ}$. This leads to a binding energy of $-549 \mathrm{~kJ} / \mathrm{mol}$ for $\mathrm{PEAH}^{+}$ and $-102 \mathrm{~kJ} / \mathrm{mol}$ for neutral PEA. Hence, the binding energy of $\mathrm{PEAH}^{+}$with the TAAR1 receptor site is over 5 times stronger than the respective binding with neutral PEA. The gaussian cube-files of the optimised geometries of PEA in the TAAR1 receptor pocket can be found in Online Resource 3.

To explore the effect of potential water and salt penetration into the TAAR1 receptor on its binding to $\mathrm{PEA} / \mathrm{PEAH}^{+}$, the protein-ligand binding properties were assessed within a range of 4-10 for the dielectric constant of the protein background. Detailed results can be found in the Supplementary Information. In summary, the variation
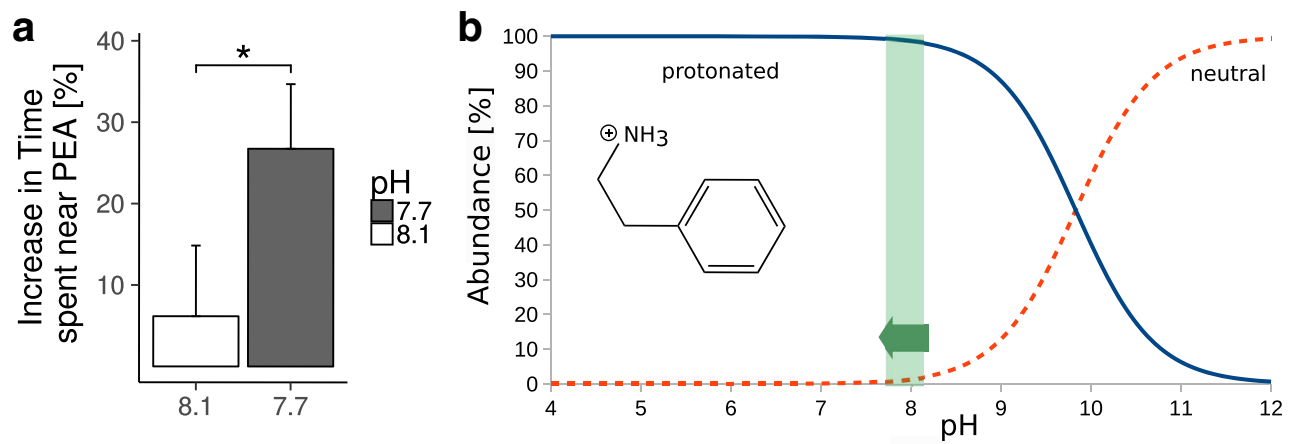

Fig. 8 Chemical and biological effect of PEA. a shows the difference in time spent in the PEA area at the highest concentration and the corresponding negative control for the two $\mathrm{pH}$ conditions [\%] with standard error bars. The asterisk indicates a significantly higher response at $\mathrm{pH} 7.7$ (one-sided t-test, $p=0.04$ ). b is a plot of the Hendersson-Hasselbalch equation for PEA to visualise the proportion of the neutral (red, dashed) and protonated (blue, solid) state present across the $\mathrm{pH}$ range. The $\mathrm{pH}$ range from 8.1 to 7.7 is shaded in green 

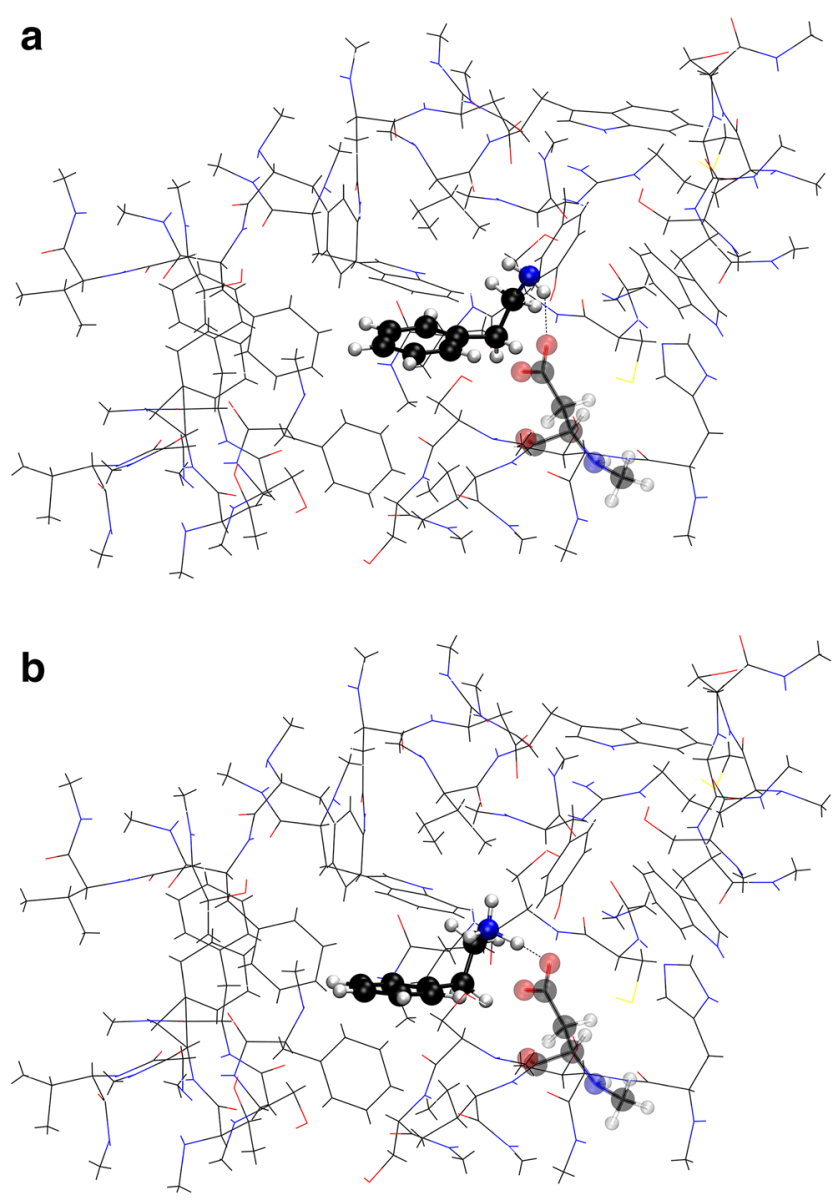

Fig. 9 Conformation of neutral (a) and protonated PEA (b) inside the TAAR1 receptor pocket. PEA and Asp103 (transparent) are shown as ball-and-stick model, whilst the rest of the binding pocket is stylised as lines

of the dielectric background leads to only small variations in the Asp103-PEA/PEAH ${ }^{+}$binding distance, $\mathrm{H}$-bond angle and $\mathrm{PEA} / \mathrm{PEAH}^{+}$conformation. Whilst the binding affinity to neutral PEA remains stable within $\pm 0.6 \mathrm{~kJ} / \mathrm{mol}$, reducing the dielectric coefficient substantially increases the binding affinity of PEAH ${ }^{+}$to TAAR1 ( $\Delta E=12 \mathrm{~kJ} / \mathrm{mol}$ ). However, across all dielectric conditions, we observe a 5-fold increase of the binding affinity upon protonation of PEA, indicating that the $\mathrm{pH}$-dependent effect dominates potential effects of the ionic environment on protein-ligand binding.

\section{Discussion}

In this study we demonstrate that PEA attracts hermit crabs, despite being a cue associated with predation for sea lampreys (Imre et al. 2014) and rodents (Ferrero et al. 2011). Furthermore, PEA was hypothesised to act as a feeding deterrent in brown and red macroalgae (Smith 1977; Van
Alstyne et al. 2019). To the best of our knowledge, this study is the first to report PEA to function as an attractant.

We were also able to demonstrate that the potency of PEA as a chemical signal increases with decreasing $\mathrm{pH}$. The threshold value for hermit crabs reacting to PEA at $\mathrm{pH} 7.7$ lays below $3 \cdot 10^{-4} \mathrm{~mol} / \mathrm{L}$, whilst at $\mathrm{pH} 8.1$, the threshold must lay above $3 \cdot 10^{-4} \mathrm{~mol} / \mathrm{L}$. Hereby, the concentrations refer to the $200 \mu \mathrm{L}$ solution on the filter paper, which functions as a target release point in the $1 \mathrm{~L}$ behaviour assay tank. As the PEA solution diffuses into the water, the true detection threshold is unknown, but should be substantially below the concentration on the filter paper. The response of hermit crabs to PEA at the highest tested concentration was significantly higher at $\mathrm{pH} 7.7$ than at $\mathrm{pH}$ 8.1. Although negative impacts of ocean acidification on marine animal behaviour predominate, some behaviours were shown to increase under elevated $\mathrm{CO}_{2}$ (reviewed in Clements and Hunt 2015). Our study indicates that PEA is one of the cues that are amplified by climate change.

Other organisms that use PEA as an actual predator cue (Imre et al. 2014), in contrast to hermit crabs, could encounter the same increased potency of the cue at decreased $\mathrm{pH}$. An increasing PEA efficiency at lower $\mathrm{pH}$ could change predator-prey interactions under climate change. The decreased threshold response to PEA would result in prey detecting predation risks at larger distances in ocean acidification scenarios, giving predators a disadvantage, whilst enhancing the chance of survival for prey.

The biological function of this predator-prey interaction cue could depend on the inhabited ecological niche and the position in the food chain. $P$. bernhardus are scavengers and known to migrate into recently trawled areas to feed on the damaged or disturbed fauna generated by beam trawling (Ramsay et al. 1996). This suggests that predation and death associated cues are attractants for hermit crabs, which is in line with our findings, but contrasts our initial expectations of a predator-related cue response. In aquatic systems dopamine, structurally very similar to PEA, induces predator associated morphological defense in waterfleas (Daphnia) (Weiss et al. 2015). As this crustacean is below hermit crabs in the food chain, this suggests a relativity of chemical communication cues depending on the role of the organism in the ecological network of the habitat.

Eavesdropping on chemical alarm cues is known to occur between species that share the same predator and cooccur spatially and temporally (Mathis and Smith 1993; Anderson and Mathis 2016). However, predators can also be attracted by the chemical alarm cue of prey, the smell of injured prey (Mathis et al. 1995; Wisenden and Thiel 2002). This reverses the biological function of an alarm cue into a feeding cue depending on the species and its position in the food chain. The attraction of secondary predators by chemical alarm cues is comparable to our findings. 
Similarily, cadaverine and putrescine are repulsive odours for zebrafish (Hussain et al. 2013), but have been reported to be feeding cues for goldfish (Rolen et al. 2003). These examples are comparable to our results, however, to the best of our knowledge, this study is the first to suggest a predator odour to attract scavengers.

Bacteria can biosynthesise PEA from organic detritus by decarboxylating phenylalanine (Marcobal et al. 2012). This supports our current findings that PEA is an attractant for hermit crabs that are known scavengers (Nickell and Moore 1992). As bacterial degradation of bioorganic matter (such as carcasses) decreases local $\mathrm{pH}$ through increased $\mathrm{CO}_{2}$ production, the increased response of hermit crabs in low $\mathrm{pH}$ is plausible. Ocean acidification is known to increase bacterial degradation activity (Piontek et al. 2010). This might promote the availability and importance of PEA as a feeding cue in future oceans. The potential pathway of $\mathrm{pH}$ interfering with the signal source is represented by pathway 1 in our scheme (Fig. 1). This is of particular interest as the efficacy of fresh food indicators such as amino acids and peptides broadly decreases with ocean acidification (Porteus et al. 2018; Roggatz et al. 2016; Roggatz et al. 2019; de la Haye et al. 2012; Velez et al. 2019). Assuming PEA acts as a detritus cue at low $\mathrm{pH}$, its increased potency could indicate that a potential shift in the diet of hermit crabs in response to ocean acidification is possible. This raises hope for adaptation processes to climate change pressures of olfactory disruption.

Considering that hermit crabs already experience large $\mathrm{pH}$ fluctuations in their intertidal environments, transgenerational acclimation might lead to a considerable potential for adaptation to climate change. Although physiological costs of climate change adaptation are likely, this study indicates that the more acidic environment might also bring some benefits for chemically-mediated behaviours.

Coastal ecosystems experience tidal, seasonal and annual natural fluctuations in acidity regardless of climate change (Wolfe et al. 2020). However, ocean acidification is known to reduce buffering of $\mathrm{pH}$ cycles (Pacella et al. 2018; Kwiatkowski and Orr 2018). Coastal diel pH extremes are expected to exceed open-ocean average $\mathrm{pH}$ changes for the end of the century (Pacella et al. 2018). Hermit crabs are therefore experiencing $\mathrm{pH}$ conditions that amplify the attraction to PEA already today. With climate change, however, its relevance is expected to increase.

Furthermore, the amplified potency of PEA at decreased $\mathrm{pH}$ suggests that the protonated state is the bioactive form. This is supported by the structural similarity of PEA to neurotransmitters, which operate at $\mathrm{pH}$ levels around 7.4 in human blood, where, following Eq. 1, 99.4\% of PEA is protonated.

As recent studies show, olfactory disruption due to ocean acidification can be closely associated with structural changes of the odour molecule (Velez et al. 2019; Roggatz et al. 2016). In our scheme (Fig. 1) this is represented by the second pathway of the $\mathrm{pH}$ influencing the signal transmission. As these molecules are operating in marine environments, it is crucial to advance our understanding of solvation models and the impact of salt to enable more realistic investigations at molecular level. Research into quantum chemical methods of ecologically relevant systems is largely underrepresented. Modelling short-range and long-range interactions of water is a trade-off between computational cost and accuracy. Implicit water models are the simplest implementation of solvation effects and computationally inexpensive. However, they only model long-range interactions with water. Our results show that the gas-phase calculations differ a lot from the solvation models (Fig. 6, see also Roggatz et al. 2018). We show that solvation stabilises the extended conformation of PEA. Especially for small molecules, short-range effects of explicitly included water molecules can add important structural information to the model. Thereby, our model coincides with findings of Bouchet et al. (2016), where the same distance between the water hydrogen atom and the $\pi$-system (2.39 $\AA$ ) was identified for the energetic minimum at absolute zero. However, our model neglects the entropy and other energetic contributions to the Gibbs free energy. As Bouchet et al. (2016) shows, these can influence the favoured position of water in the folded conformation and might be crucial for the correct representation of solvation effects. Nevertheless, for PEA the energy difference between the conformers (Table 1) is comparable to those at room temperature when the Gibbs free energy is considered (Bouchet et al. 2016). Further studies are being conducted to extend the current solvation models and promote our understanding of the conformation of small molecules such as odour cues in water.

The quantum chemical calculations for protonated and neutral PEA reveal differences in the conformation (Fig. 6) and the dipole moment (Fig. 7) for the different protonation states. The observed conformational changes, on the one hand, are small and might not affect receptor-ligand interactions. In analogy to dopamine, the amino group could act as the anchoring point within the receptor followed by a rapid rearrangement of the conformation (Andujar et al. 2011). Considering the small change in the amount of active compound $(1.3 \%)$ within the range of ocean acidification, it is unlikely that conformational changes of PEA account for the change in hermit crab behaviour. The dipole, on the other hand, increases 5-fold upon protonation. In contrast to conformational effects, increasing the electric interactions between receptor and ligand can significantly affect their interplay and accelerate the binding (discussed further below, Radić et al. 1997; Wade et al. 1998). In mammals, PEA is a known dopamine receptor agonist (Barroso and 
Rodriguez 1996) and binds to olfactory TAAR receptors as well as the TAAR1 receptor in the brain, which regulates neuronal excitability (Liberles 2015). However, although PEA is a neurotransmitter and predator odour for mammals, similar functions in hermit crabs remain unknown.

To provide a proof of principle, we modelled the changes in the receptor-ligand interaction upon protonation of the ligand using the human TAAR1 receptor. To the best of our knowledge, this study is the first to include the effects of ocean acidification on receptor-ligand binding. Our results coincide with findings of Cichero et al. (2013), where the folded conformation of $\mathrm{PEAH}^{+}$was found to bind to Asp103. Furthermore, protonated dopamine and its D2 binding pocket (Andujar et al. 2011) are similar in structure and binding mechanism to the PEA-TAAR1 complex, which allows us to compare the models. Whilst we report a folded conformation of PEA (torsion angle $\tau=83^{\circ}$ for neutral and $67^{\circ}$ for $\mathrm{PEAH}^{+}$) when binding to Asp103 in TAAR1, dopamine also adopts a folded conformation $(\tau=$ $78^{\circ}$ ) in interaction with Asp86 of the dopamine D2 receptor at the global minimum (Andujar et al. 2011). Additionally, the distance between the nitrogen atom of PEA and the aspartate oxygen atom is $3.1 \AA$ for neutral and $2.5 \AA$ for protonated PEA, whilst similarly, the aspartate binding point of the dopamine D2 receptor establishes a distance of $2.9 \AA$ with the nitrogen atom of dopamine (Andujar et al. 2011). Furthermore, these models of $G$ protein-coupled receptors are within the range of heavy atom distances of the $\mathrm{N}-\mathrm{H}$ and $\mathrm{O}$ bonds generally observed in proteinligand interactions (de Freitas and Schapira 2017). Also, hydrogen bond angles in protein-ligand interactions were reported to peak at $130-180^{\circ}$ (de Freitas and Schapira 2017), which includes our reported angles of $147^{\circ}$ for neutral and $170^{\circ}$ for protonated PEA. The quantum chemical calculations show that the 5-fold increase of the dipole upon protonation of the ligand leads to a more than 5fold increase in the binding affinity between receptor and ligand (Fig. 9). This suggests an increased retention time at decreased $\mathrm{pH}$. However, the relationship between binding affinity and retention time is not necessarily linear. The strength of the receptor-ligand binding affects dissociation and association constants differently (Pan et al. 2013). Radić et al. (1997) demonstrated the importance of electrostatic interactions for protein-ligand interactions by comparing the association and dissociation rates of acetylcholinesterase inhibitors. Binding with the positively charged inhibitor $m$-trimethylammoniotrifluoroacetopherone was 400-fold faster and unbinding 10-fold slower than with a neutral analogue, where a positively charged nitrogen atom was exchanged for a carbon atom in the trimethylammonium group (Radić et al. 1997).

Whilst we show that the changes in the charge of the odour molecule could account for the altered hermit crab behaviour at decreased $\mathrm{pH}$, other factors also have to be taken into consideration. As shown by pathway 4 in our scheme (Fig. 1), the pH can affect the signal transduction. Ocean acidification is known to alter brain ion gradients in fish, affecting the GABA signalling pathway (Heuer et al. 2016; Nilsson et al. 2012; Williams et al. 2019). However, de la Haye et al. (2012) showed that, unlike for fish, hermit crab heamolymph showed no change in ionic concentrations that correlated with the locomotory activity when exposed to low $\mathrm{pH}$ conditions. This suggests an impairment of the chemoreception (represented by pathway 3 in Fig. 1) rather than an interference with signal transduction in hermit crabs (arrow 4 in Fig. 1).

This study shows that for PEA, changes in the binding affinity to the receptor could be responsible for the observed change in behaviour. This is in line with a previous study by Porteus et al. (2018) showing that ocean acidification can impair the olfactory system of marine fish. However, whether the altered chemoreception is primarily attributed to changes in the odorant molecule, the olfactory receptor structure or the olfactory epithelium, might depend on the studied system (Velez et al. 2019).

Furthermore, this study explores how different salinities affect the computational models of PEA/PEAH ${ }^{+}$in water and in the TAAR1 receptor by manipulating the dielectric constant in the solvation models. Our computational results suggest that conformation, charge separation and conformational preference of the small odour molecules PEA and $\mathrm{PEAH}^{+}$in water are unaffected by changes in salinity and temperature within a range relevant for British coastal waters (see Suppl. Fig. 3). Similarly, inside the binding pocket of TAAR1, the binding parameters of the $\mathrm{H}$-bond and the conformation of PEA and $\mathrm{PEAH}^{+}$was comparable across all dielectric environments. However, whilst the binding affinity of PEA is unaffected by changes in water and salt penetration into TAAR1, the binding strength of $\mathrm{PEAH}^{+}$with its model receptor increases with increasing salt concentrations (see Suppl. Fig. 4). Nevertheless, the $\mathrm{pH}$-dependent effects on protein-ligand binding in our models clearly outweigh the observed salinity-dependent effects.

It is also important to note that the basic building blocks of receptors are amino acids which are known to be sensitive to $\mathrm{pH}$ (Tierney and Atema 1988). As olfactory receptors are in almost direct contact with the environment, their sensitivity to external conditions seems plausible. In addition to $\mathrm{pH}$ related changes in receptorligand interactions, changes in the receptors themselves are possible. Although shielded by water and salt (see also Supplementary Information), protonation of an amino acid inside the TAAR1 binding pocket could render the negatively charged binding site neutral, thereby drastically changing the electrostatic receptor-ligand interactions. 
Pharmaceutical studies on $G$ protein-coupled receptors demonstrate the effect of altered $\mathrm{pH}$ on receptor functioning (D'Souza and Strange 1995; Gillard and Chatelain 2006; King et al. 1997). They show that changes in just a few amino acids, caused by a drop in $\mathrm{pH}$, can lead to fundamental changes in the receptor, altering association and dissociation rates of ligands. Studies on pheromone binding mechanisms in insects have also shown that $\mathrm{pH}$ induced conformational changes can play a major role in the ligand-protein interaction (Di Luccio et al. 2013; Yin et al. 2015).

As the PEA receptor in hermit crabs is unknown, we assume an aspartate-based binding mechanism for our model, similar to the human TAAR1 receptor. It is important to note that explicit solvation effects have been neglected in the receptor model. The effect of water on the binding mechanism remains to be explored. Although we don't know the binding mechanism of PEA in hermit crabs, the demonstrated preferential binding of $\mathrm{PEAH}^{+}$over neutral PEA provides an explanation for the observed behavioural change. All other potential mechanistic approaches were unable to account for the altered behaviour at increased $\mathrm{pH}$. While the direct link between the observed behavioural effects and the modelled changes in the molecular properties of PEA remains to be uncovered in full, the computational receptor-ligand modelling is a proof-of-concept model that points towards a new mechanistic pathway. Our current findings highlight that the change in the efficacy of a signalling cue is not necessarily linear to its protonation state abundance. Protonation can lead to changes in the dipole moment of a chemical cue, which can substantially alter protein-ligand electrostatic interactions. As the TAAR1 binding site is negatively charged, the increased dipole moment of $\mathrm{PEAH}^{+}$over PEA substantially increases the electrostatic binding affinity. Subsequent changes in the receptor retention time can largely deviate in scale from the difference in protonation state abundance.

In contrast to previous studies (Roggatz et al. 2016; Porteus et al. 2018; Velez et al. 2019), we chose to manipulate only the proton concentration in the sea water. Thereby, we were able to show the isolated effect of $\mathrm{pH}$-induced conformational changes on the chemical cue and its interaction with a receptor. Our findings promote the understanding of the underlying mechanisms of ocean acidification effects on chemoreception by disentangling the effects of decreasing $\mathrm{pH}$ and increasing $\mathrm{CO}_{2}$. However, increasing $\mathrm{CO}_{2}$ levels can have wide-ranging physiological effects that are not included in this study. Building on this work, a comparison of the effect of changing $\mathrm{pH}$ through $\mathrm{CO}_{2}$ and acids could further advance our understanding of how ocean acidification interferes with the sense of smell.

\section{Conclusion}

We were able to demonstrate that PEA is an attractant for hermit crabs whilst being widely associated as a predator cue in other animals. In addition, the response to PEA depends on the $\mathrm{pH}$ within a range relevant for ocean acidification scenarios by 2100 and $\mathrm{pH}$ fluctuations in intertidal habitats. Interestingly, decreasing the $\mathrm{pH}$ amplifies the effect of PEA. Further research is needed to promote our understanding of the role of PEA for other organisms in current and future oceans. Using quantum chemical methods we provide a potential mechanistic explanation for the observed behavioural effect. We show that the altered electronic properties can impact the receptor-ligand affinity and thereby affect the retention time of the ligand. Future research should consider modelling $\mathrm{pH}$-dependent changes in the receptor site, the chemical cue as well as their interaction. This study provides a rare example of a chemically-mediated behaviour that is enhanced in future ocean conditions and showcases the power of cross-disciplinary research to help unravel the underlying mechanisms.

Supplementary Information The online version contains supplementary material available at https://doi.org/10.1007/s10886-021-01276-9.

Acknowledgements We acknowledge the Viper High Performance Computing facility of the University of Hull and its support team. The authors would also like to thank Dr. R. Terschak and V. Swetez for technical and animal husbandry support and Dr. R. Lewis for advice and help with NMR spectroscopy. PS is financially supported by the University of Hull, UK, as part of a PhD project cluster. CCR acknowledges funding through ERC-2016-COG GEOSTICK (Project ID: 725955) and a University of Hull Vice-Chancellor Research Fellowship.

\section{Declarations}

Conflict of interests The authors declare that they have no conflict of interest.

Open Access This article is licensed under a Creative Commons Attribution 4.0 International License, which permits use, sharing, adaptation, distribution and reproduction in any medium or format, as long as you give appropriate credit to the original author(s) and the source, provide a link to the Creative Commons licence, and indicate if changes were made. The images or other third party material in this article are included in the article's Creative Commons licence, unless indicated otherwise in a credit line to the material. If material is not included in the article's Creative Commons licence and your intended use is not permitted by statutory regulation or exceeds the permitted use, you will need to obtain permission directly from the copyright holder. To view a copy of this licence, visit http://creativecommons. org/licenses/by/4.0/. 


\section{References}

Adamo C, Barone V (1999) Toward reliable density functional methods without adjustable parameters: The pbe0 model. J Chem Phys 110(13):6158-6170. https://doi.org/10.1063/1.478522

Anderson K, Mathis A (2016) Friends in low places: Responses of a bethic stream fish to intra-prey-guild alarm cues. Ethology 122(12):954-962. https://doi.org/10.1111/eth.12563

Andujar S, Tosso R, Suvire F, Angelina E, Peruchena N, Cabedo N, Cortes D, Enriz R (2011) Searching the "biologically relevant" conformation of dopamine: a computational approach. J Chem Inf Model 52(1):99-112. https://doi.org/10.1021/ci2004225

Barone V, Cossi M (1998) Quantum calculation of molecular energies and energy gradients in solution by a conductor solvent model. J Phys Chem A 102(11):1995-2001. https://doi.org/ 10.1021/jp9716997

Barroso N, Rodriguez M (1996) Action of $\beta$-phenylethylamine and related amines on nigrostriatal dopamine neurotransmission. European J Pharmacol 297(3):195-203. https://doi.org/10.1016/ 0014-2999(95)00757-1

Bates D, Mächler M, Bolker B, Walker S (2015) Fitting linear mixed-effects models using lme4. J Stat Softw 67(1):1-48. https:// doi.org/10.18637/jss.v067.i01

Blöchl P (1995) Electrostatic decoupling of periodic images of planewave-expanded densities and derived atomic point charges. J Chem Phys 103(17):7422-7428. https://doi.org/10.1063/1.470314

Bode B, Gordon M (1998) Macmolplt: a graphical user interface for gamess. J Mol Graph Model 16(3):133-138. https://doi.org/ 10.1016/S1093-3263(99)00002-9

Böhm HJ, Brode S, Hesse U, Klebe G (1996) Oxygen and nitrogen in competitive situations: Which is the hydrogen-bond acceptor? Chem Eur J 2(12):1509-1513. https://doi.org/10.1002/ chem.19960021206

Bopp L, Resplandy L, Orr J, Doney S, Dunne J, Gehlen M, P H, Heinze C, Ilyina T, Séférian R, Tjiputra J, Vichi M (2013) Multiple stressors of ocean ecosystems in the 21st century: projections with cmip5 models. Biogeosciences 10:6225-6245. https://doi.org/10.5194/bg-10-6225-2013

Bouchet A, Schütz M, Chiavarino B, Crestoni M, Fornarini S, Dopfer O (2015) IR spectrum of the protonated neurotransmitter 2-phenylethylamine: dispersion and anharmonicity of the $\mathrm{NH}_{3}^{+}$$\pi$ interaction. Phys Chem Chem Phys 17(39):25742-25754. https://doi.org/10.1039/C5CP00221D

Bouchet A, Schütz M, Dopfer O (2016) Competing insertion and external binding motifs in hydrated neurotransmitters: Infrared spectra of protonated phenylethylamine monohydrate. Chem Phys Chem 17(2):232-243. https://doi.org/10.1002/cphc.201500939

Brown G, Adrian JrJ, Lewis M, Tower J (2002) The effects of reduced $\mathrm{pH}$ on chemical alarm signalling in ostariophysan fishes. Can J Fish Aquat Sci 59(8):1331-1338. https://doi.org/10.1139/f02-104

Chiavarino B, Crestoni M, Schütz M, Bouchet A, Piccirillo S, Steinmetz V, Dopfer O, Fornarini S (2014) Cation- $\pi$ interactions in protonated phenylalkylamines. J Phys Chem A 118(34):7130 7138. https://doi.org/10.1021/jp505037n

Cichero E, Espinoza S, Gainetdinov R, Brasili L, Fossa P (2013) Insights into the structure and pharmacology of the human trace amine-associated receptor 1 ( $h$ taar1): Homology modelling and docking studies. Chem Biol Drug Des 81(4):509-516. https://doi.org/10.1111/cbdd.12018

Clements J, Hunt $\mathrm{H}$ (2015) Marine animal behaviour in a high $\mathrm{CO}_{2}$ ocean. Mar Ecol Prog Ser 536:259-279. https://doi.org/10.3354/ meps 11426

Cohen J, Forward R Jr (2003) Ctenophore kairomones and modified aminosugar disaccharides alter the shadow response in a larval crab. J Plankton Res 25(2):203-213. https://doi.org/10.1093/ plankt/25.2.203
Cossi M, Rega N, Scalmani G, Barone V (2003) Energies, structures, and electronic properties of molecules in solution with the c-pcm solvation model. J Comput Chem 24(6):669-681. https://doi.org/10.1002/jcc.10189

de Freitas R, Schapira M (2017) A systematic analysis of atomic protein-ligand interactions in the pdb. Medchemcomm 8(10):1970-1981. https://doi.org/10.1039/C7MD00381A

de la Haye K, Spicer J, Widdicombe S, Briffa M (2012) Reduced $\mathrm{pH}$ sea water disrupts chemo-responsive behaviour in an intertidal crustacean. J Exp Mar Bio Ecol 412:134-140. https://doi.org/ 10.1016/j.jembe.2011.11.013

Di Luccio E, Ishida Y, Leal W, Wilson D (2013) Crystallographic observation of $\mathrm{pH}$-induced conformational changes in the Amyelois transitella pheromone-binding protein AtraPBP1. PLoS One 8(2):e53840. https://doi.org/10.1371/journal.pone.0053840

Di Rocco R, Imre I, Johnson N, Brown G (2016) Behavioural response of adult sea lamprey (Petromyzon marinus) to predator and conspecific alarm cues:, evidence of additive effects. Hydrobiologia 767(1):279-287. https://doi.org/10.1007/s10750-015-2508-6

Dickinson J, Hockridge M, Kroemer R, Robertson E, Simons J, McCombie J, Walker M (1998) Conformational choice, hydrogen bonding, and rotation of the $s_{1} \leftarrow s_{0}$ electronic transition moment in 2-phenylethyl alcohol, 2-phenylethylamine, and their water clusters. J Am Chem Soc 120(11):2622-2632. https://doi.org/10.1021/ja972104o

Doney S, Fabry V, Feely R, Kleypas J (2009) Ocean acidification: the other $\mathrm{CO}_{2}$ problem. Ann Rev Mar Sci https://doi.org/10.1146/ annurev.marine.010908.163834

D'Souza U, Strange P (1995) $\mathrm{pH}$ dependence of ligand binding to $\mathrm{D}_{2}$ dopamine receptors. Biochemistry 34(41):13635-13641. https://doi.org/10.1021/bi00041a044, http://pubs.acs.org/doi/abs/ 10.1021/bi00041a044

Ferrero D, Lemon J, Fluegge D, Pashkovski S, Korzan W, Datta S, Spehr M, Fendt M, Liberles S (2011) Detection and avoidance of a carnivore odor by prey. PNAS 108(27):11235-11240. https://doi.org/10.1073/pnas.1103317108

Fitch CA, Karp DA, Lee KK, Stites WE, Lattman EE, GarcíaMoreno EB (2002) Experimental $\mathrm{pK}_{a}$, values of buried residues: Analysis with continuum methods and role of water penetration. Biophys J 82(6):3289-3304. https://doi.org/10.1016/S00063495(02)75670-1

Gattuso JP, Lee K, Rost B, Schulz K (2010) Approaches and tools to manipulate the carbonate chemistry. Publications Office of the European Union

Gherardi F, Tricarico E (2010) Chemical ecology and social behavior of anomura. In: Chemical communication in crustaceans. Springer, pp 297-312

Gillard M, Chatelain P (2006) Changes in pH differently affect the binding properties of histamine $\mathrm{h} 1$ receptor antagonists. European J Pharmacol 530(3):205-214. https://doi.org/10.1016/ j.ejphar.2005.11.051

Godfrey P, Hatherley L, Brown R (1995) The shapes of neurotransmitters by millimeter-wave spectroscopy: 2-phenylethylamine. J Am Chem Soc 117(31):8204-8210. https://doi.org/10.1021/ja 00136a019

Grimme S, Antony J, Ehrlich S, Krieg H (2010) A consistent and accurate $a b$ initio parametrization of density functional dispersion correction (dft-d) for the 94 elements h-pu. J Chem Phys 132(15):154104. https://doi.org/10.1063/1.3382344

Grimme S, Ehrlich S, Goerigk L (2011) Effect of the damping function in dispersion corrected density functional theory. J Comput Chem 32(7):1456-1465. https://doi.org/10.1002/jcc.21759

Hahn MA, Effertz C, Bigler L, von Elert E (2019) $5 \alpha$-cyprinol sulfate, a bile salt from fish, induces diel vertical migration in daphnia. eLife 8:e44791. https://doi.org/10.7554/eLife.44791 
Hanwell DM, Curtis D, Lonie D, Vandermeersch T, Zurek E, Hutchison G (2012) Avogadro: An advanced semantic chemical editor, visualization, and analysis platform. J Cheminform 4(1):17. https://doi.org/10.1186/1758-2946-4-17

Hasted JB, Ritson DM, Collie CH (1948) Dielectric properties of aqueous ionic solutions. parts i and ii. J Chem Phys 16(1):1-21. https://doi.org/10.1063/1.174664516

Hay M (2009) Marine chemical ecology: chemical signals and cues structure marine populations, communities, and ecosystems. Ann Rev Mar Sci 1:193-212. https://doi.org/10.1146/annurev.marine. 010908.163708

Hazlett B (1981) The behavioral ecology of hermit crabs. Annu Rev Ecol System 12(1):1-22

Heuer R, Welch M, Rummer J, Munday P, Grosell M (2016) Altered brain ion gradients following compensation for elevated $\mathrm{CO}_{2}$ are linked to behavioural alterations in a coral reef fish. Sci Rep 6:33216. https://doi.org/10.1038/srep33216

Hockridge M, Robertson E (1999) Hydrated clusters of 2-phenylethyl alcohol and 2-phenylethylamine: Structure, bonding, and rotation of the $\mathrm{s}_{1} \leftarrow \mathrm{s}_{0}$ electronic transition moment. J Phys Chem A (19)3618-3628. https://doi.org/10.1021/jp9900077

Hothorn T, Bretz F, Westfall P (2008) Simultaneous inference in general parametric models. Biom J 50(3):346-363

Hussain A, Saraiva L, Ferrero D, Ahuja G, Krishna V, Liberles S, Korsching S (2013) High-affinity olfactory receptor for the death-associated odor cadaverine. PNAS 110(48):19579-19584. https://doi.org/10.1073/pnas.1318596110

Hutter J, Iannuzzi M, Schiffmann F, VandeVondele J (2014) cp2k: atomistic simulations of condensed matter systems. WIREs Comput Mol Sci 4(1):15-25. https://doi.org/10.1002/wcms.1159

Imre I, di Rocco R, Belanger C, Brown G, Johnson N (2014) The behavioural response of adult Petromyzon marinus to damagereleased alarm and predator cues. J Fish Biol 84(5):1490-1502. https://doi.org/10.1111/jfb.12374

IPCC (2014) Climate change 2014: synthesis report. Contribution of Working Groups I, II and III to the fifth assessment report of the Intergovernmental Panel on Climate Change, IPCC

Jensen F (2001) Polarization consistent basis sets: principles. J Chem Phys 115:9113-9125. https://doi.org/10.1063/1.1413524

Jensen F (2002a) Polarization consistent basis sets. ii. estimating the kohn-sham basis set limit. J Chem Phys 116:7372-7379. https://doi.org/10.1063/1.1465405

Jensen F (2002b) Polarization consistent basis sets. iii. the importance of diffuse functions. J Chem Phys 117:9234-9240. https://doi.org/ $10.1063 / 1.1515484$

King B, Wildman S, Ziganshina L, Pintor J, Burnstock G (1997) Effects of extracellular $\mathrm{pH}$ on agonism and antagonism at a recombinant $\mathrm{p} 2 \mathrm{x}_{2}$ receptor. Br J Pharmacol 121(7):1445-1453. https://doi.org/10.1038/sj.bjp.0701286

Klein L, Swift C (1977) An improved model for the dielectric constant of sea water at microwave frequencies. IEEE Trans Antennas Propag 25(1):104-111. https://doi.org/10.1109/TAP.1977.1141 539

Krack M (2005) Pseudopotentials for $\mathrm{H}$ to $\mathrm{Kr}$ optimized for gradientcorrected exchange-correlation functionals. Theor Chem Acc 114(1-3):145-152. https://doi.org/10.1007/s00214-005-0655-y

Kutzelnigg W, Fleischer U, Schindler M (1990) The iglo-method: ab-initio calculation and interpretation of NMR chemical shifts and magnetic susceptibilities. In: Deuterium and shift calculation. Springer, pp 165-262

Kwiatkowski L, Orr JC (2018) Diverging seasonal extremes for ocean acidification during the twenty-first century. Nat Clim Chang 8(2):141-145. https://doi.org/10.1038/s41558-017-0054-0
Lancaster I (1988) Pagurus bernhardus (1.) - an introduction to the natural history of hermit crabs. Field Stud 7:189-238

Landschützer P, Gruber N, Bakker DCE, Stemmler I, Six KD (2018) Strengthening seasonal marine $\mathrm{CO}_{2}$ variations due to increasing atmospheric $\mathrm{CO}_{2}$. Nat Clim Chang 8(2):146-150. https://doi.org/ 10.1038/s41558-017-0057-x

Leckband D, Israelachvili J, Schmitt F, Knoll W (1992) Long-range attraction and molecular rearrangements in receptor-ligand interactions. Science 255(5050):1419-1421. https://doi.org/10.1126/ science. 1542789

Liberles SD (2015) Trace amine-associated receptors: ligands, neural circuits, and behaviors. Curr Opin Neurobiol 34:1-7. https://doi.org/10.1016/j.conb.2015.01.001

Lide D (ed) (2000) CRC Handbook of Chemistry and Physics, 81st edn. CRC Press LLC

López J, Cortijo V, Blanco S, Alonso J (2007) Conformational study of 2-phenylethylamine by molecular-beam fourier transform microwave spectroscopy. Phys Chem Chem Phys 9(32):45214527. https://doi.org/10.1039/B705614A

Marcobal A, De Las Rivas B, Landete JM, Tabera L, Muñoz R (2012) Tyramine and phenylethylamine biosynthesis by food bacteria. Crit Rev Food Sci Nutr 52(5):448-467. https://doi.org/10.1080/ 10408398.2010.500545

Martyna G, Tuckerman M (1999) A reciprocal space based method for treating long range interactions in ab initio and force-fieldbased calculations in clusters. J Chem Phys 110(6):2810-2821. https://doi.org/10.1063/1.477923

Mathis A, Smith R (1993) Intraspecific and cross-superorder responses to chemical alarm signals by brook stickleback. Ecology 74(8):2395-2404. https://doi.org/10.2307/1939590

Mathis A, Chivers D, Smith R (1995) Chemical alarm signals: predator deterrents or predator attractants? Am Nat 145(6):994-1005. https://doi.org/10.1086/285780

Melandri S, Maris A, Giuliano B, Favero L, Caminati W (2010) The free jet microwave spectrum of 2-phenylethylamine-water. Phys Chem Chem Phys 12(35):10210. https://doi.org/10.1039/c003 $513 \mathrm{k}$

Neese F (2012) The orc a program system. WIREs Comput Mol Sci 2(1):73-78. https://doi.org/10.1002/wcms.81

Neese F (2018) Software update: the orca program system, version 4.0. WIREs Comput Mol Sci 8(1):e1327. https://doi.org/ $10.1002 /$ wcms. 1327

Neese F, Wennmohs F, Hansen A, Becker U (2009) Efficient, approximate and parallel hartree-fock and hybrid DFT calculations. a "chain-of-spheres" algorithm for the hartree-fock exchange. Chem Phys 356(1-3):98-109. https://doi.org/10.1016/ j.chemphys.2008.10.036

Nickell T, Moore P (1992) The behavioural ecology of epibenthic scavenging invertebrates in the clyde sea area: laboratory experiments on attractions to bait in moving water, underwater tv observation in situ and general conclusions. J Exp Mar Bio Ecol 159(1):15-35. https://doi.org/10.1016/0022-0981(92)90 255-9

Nilsson G, Dixson D, Domenici P, McCormick M, Sørensen C, Watson SA, Munday P (2012) Near-future carbon dioxide levels alter fish behaviour by interfering with neurotransmitter function. Nat Clim Chang 2(3):201-204. https://doi.org/10.1038/ nclimate 1352

NOAA N (2019) State of the climate: Global climate report for annual 2018. www.ncdc.noaa.gov/sotc/global/201813

Pacella SR, Brown CA, Waldbusser GG, Labiosa RG, Hales B (2018) Seagrass habitat metabolism increases short-term extremes and long-term offset of $\mathrm{CO}_{2}$ under future ocean acidification. 
PNAS 115(15):3870-3875. https://doi.org/10.1073/pnas.170344 5115

Pan A, Borhani D, Dror R, Shaw D (2013) Molecular determinants of drug-receptor binding kinetics. Drug Discov Today 18(1314):667-673. https://doi.org/10.1016/j.drudis.2013.02.007

Pándy-Szekeres G, Munk C, Tsonkov T, Mordalski S, Harpsøe K, Hauser A, Bojarski A, Gloriam D (2018) CPCRdb in 2018:, adding CPCR structure models and ligands. Nucleic Acids Res 46(D1):D440-D446. https://doi.org/10.1093/nar/gkx1109

Percot A, Yalçın A, Aysel V, Erdugan H, Dural B, Güven K (2009) $\beta$ phenylethylamine content in marine algae around turkish coasts. Botanica Marina 52(1):87-90. https://doi.org/10.1515/BOT.2009. 031

Perdew J, Burke K, Ernzerhof M (1996) Generalized gradient approximation made simple. Phys Rev Lett 77(18):3865. https://doi.org/10.1103/PhysRevLett.77.3865

Piontek J, Lunau M, Händel N, Borchard C, Wurst M, Engel A (2010) Acidification increases microbial polysaccharide degradation in the ocean. Biogeosciences 7(5):1615-1624. https://doi.org/ $10.5194 / \mathrm{bg}-7-1615-2010$

Porteus C, Hubbard P, Uren Webster T, van Aerle R, Canário A, Santos E, Wilson R (2018) Near-future $\mathrm{CO}_{2}$ levels impair the olfactory system of a marine fish. Nat Clim Chang 8(737):737743. https://doi.org/10.1038/s41558-018-0224-8

Poulin R, Lavoie S, Siegel K, Gaul D, Weissburg M, Kubanek $\mathrm{J}$ (2018) Chemical encoding of risk perception and predator detection among estuarine invertebrates. PNAS 115(4):662-667. https://doi.org/10.1073/pnas.1713901115

R Core Team (2015) R: A Language and Environment for Statistical Computing. R Foundation for Statistical Computing, Vienna, Austria. https://www.R-project.org/

Radić Z, Kirchhoff P, Quinn D, McCammon J, Taylor P (1997) Electrostatic influence on the kinetics of ligand binding to acetylcholinesterase distinctions between active center ligands and fasciculin. J Biol Chem 272(37):23265-23277. https://doi.org/10.1074/ jbc. 272.37 .23265

Ramsay K, Kaiser M, Hughes R (1996) Changes in hermit crab feeding patterns in response to trawling disturbance. Mar Ecol Prog Ser 144:63-72. https://doi.org/10.3354/meps144063

Rappé A, Casewit C, Colwell K, Goddard III W, Skiff W (1992) Uff, a full periodic table force field for molecular mechanics and molecular dynamics simulations. J Am Chem Soc 114(25):1002410035. https://doi.org/10.1021/ja00051a040

Ristić M, Petković M, Milovanović B, Belić J, Etinski M (2019) New hybrid cluster-continuum model for $\mathrm{pK}_{a}$ values calculations: Case study of neurotransmitters' amino group acidity. Chem Phys 516:55-62. https://doi.org/10.1016/j.chemphys.2018.08.022

Roggatz C, Kenningham N, Bartels-Hardege H (2019) Taking Current Climate Change Research to the Classroom-The "Will Hermit Crabs Go Hungry in Future Oceans?" Project. In: Climate Change and the Role of Education. Springer, pp. 255-277

Roggatz C, Lorch M, Hardege J, Benoit D (2016) Ocean acidification affects marine chemical communication by changing structure and function of peptide signalling molecules. Glob Chang Biol 22(12):3914-3926. https://doi.org/10.1111/gcb.13354

Roggatz C, Lorch M, Benoit D (2018) Influence of solvent representation on nuclear shielding calculations of protonation states of small biological molecules. J Chem Theory Comput 14(5):2684-2695. https://doi.org/10.1021/acs.jctc.7b01020

Rolen S, Sorensen P, Mattson D, Caprio J (2003) Polyamines as olfactory stimuli in the goldfish carassius auratus. J Exp Biol 206(10):1683-1696. https://doi.org/10.1242/jeb.00338

Rosen E, Schwarz B, Palmer AR (2009) Smelling the difference: hermit crab responses to predatory and nonpredatory crabs.
Anim Behav 78(3):691-695. https://doi.org/10.1016/j.anbehav. 2009.05.035

Schmidt M, Baldridge K, Boatz J, Elbert S, Gordon M, Jensen J, Koseki S, Matsunaga N, Nguyen K, Su S (1993) General atomic and molecular electronic structure system. J Comput Chem 14(11):1347-1363. https://doi.org/10.1002/jcc.540141112

Siefkes M (2017) Use of physiological knowledge to control the invasive sea lamprey (Petromyzon marinus) in the laurentian great lakes. Conserv Physiol 5(1) https://doi.org/10.1093/conphys/ cox031

Siegbahn P, Himo F (2009) Recent developments of the quantum chemical cluster approach for modeling enzyme reactions. J Biol Inorg Chem 14(5):643-651. https://doi.org/10.1007/s00775-0090511-y

Smith T (1977) Phenethylamine and related compounds in plants. Phytochemistry 16(1):9-18. https://doi.org/10.1016/0031-9422(77) 83004-5

Steiner M, Hartmann T (1968) The occurence and distribution of volatile amines in marine algae. Planta 79(2):113-121. https://doi. org/10.1007/BF00390154

Tierney A, Atema T (1988) Amino acid chemoreception: effects of $\mathrm{pH}$ on receptors and stimuli. J Chem Ecol 14(1):135-141. https://doi.org/10.1007/BF01022537

Van Alstyne K, Ridgway R, Nelson T (2019) Neurotransmitters in marine and freshwater algae. In: Ramakrishna A, Roshchina V (eds). CRC Press, Neurotransmitters in Plants, pp 35-54. https:// doi.org/10.1201/b22467-3

VandeVondele J, Hutter J (2007) Gaussian basis sets for accurate calculations on molecular systems in gas and condensed phases. J Chem Phys 127(11):114105. https://doi.org/10.1063/1. 2770708

VandeVondele J, Krack M, Mohamed F, Parrinello M, Chassaing T, Hutter J (2005) Quickstep: Fast and accurate density functional calculations using a mixed gaussian and plane waves approach. Comput Phys Commun 167(2):103-128. https://doi.org/10.1016/j.cpc.2004.12.014

Velez Z, Roggatz C, Benoit D, Hardege J, Hubbard P (2019) Short-and medium-term exposure to ocean acidification reduces olfactory sensitivity in gilthead seabream. Front Physiol 10:731. https://doi.org/10.3389/fphys.2019.00731

Wade RC, Gabdoulline RR, Lüdemann SK, Lounnas V (1998) Electrostatic steering and ionic tethering in enzyme-ligand binding: Insights from simulations. PNAS 95(11):5942-5949. https://doi.org/10.1073/pnas.95.11.5942

Weigend F (2006) Accurate coulomb-fitting basis sets for $\mathrm{H}$ to $\mathrm{Rn}$. Phys Chem Chem Phys 8(9):1057-1065. https://doi.org/10.1039/ B515623H

Weiss L, Leese F, Laforsch C, Tollrian R (2015) Dopamine is a key regulator in the signalling pathway underlying predator-induced defences in Daphnia. Proc R Soc B Biol Sci 282(1816):20151440. https://doi.org/10.1098/rspb.2015.1440

Williams C, Dittman A, McElhany P, Busch D, Maher M, Bammler T, MacDonald J, Gallagher E (2019) Elevated $\mathrm{CO}_{2}$ impairs olfactory-mediated neural and behavioral responses and gene expression in ocean-phase coho salmon (Oncorhynchus kisutch). Glob Chang Biol 25(3):963-977. https://doi.org/10.1111/gcb. https://doi.org/10.1111/gcb.1453214532

Wisenden B, Thiel T (2002) Field verification of predator attraction to minnow alarm substance. J Chem Ecol 28(2):433-438. https://doi.org/10.1023/A:1017950628284

Wolfe K, Nguyen HD, Davey M, Byrne M (2020) Characterizing biogeochemical fluctuations in a world of extremes: A synthesis for temperate intertidal habitats in the face of global change. Glob Chang Biol https://doi.org/10.1111/gcb.15103 
Wong M, Frisch M, Wiberg K (1991) Solvent effects. 1. the mediation of electrostatic effects by solvents. J Am Chem Soc 113(13):47764782. https://doi.org/10.1021/ja00013a010

Yin J, Choo Y, Duan H, Leal W (2015) Selectivity of odorantbinding proteins from the southern house mosquito tested against physiologically relevant ligands. Front Physiol 6(56) https://doi.org/10.3389/fphys.2015.00056
Zhang D, Zhang J (2003) Molecular fractionation with conjugate caps for full quantum mechanical calculation of proteinmolecule interaction energy. J Chem Phys 119(7):3599-3605. https://doi.org/10.1063/1.1591727

Publisher's Note Springer Nature remains neutral with regard to jurisdictional claims in published maps and institutional affiliations. 